\title{
Validation of MIPAS-ENVISAT $\mathrm{NO}_{2}$ operational data
}

\author{
G. Wetzel ${ }^{1}$, A. Bracher ${ }^{2}$, B. Funke ${ }^{3}$, F. Goutail ${ }^{4}$, F. Hendrick 5 , J.-C. Lambert ${ }^{5}$, S. Mikuteit ${ }^{1}$, C. Piccolo ${ }^{6}$, M. Pirre ${ }^{7}$, \\ A. Bazureau ${ }^{4}$, C. Belotti ${ }^{8}$, T. Blumenstock ${ }^{1}$, M. De Mazière ${ }^{5}$, H. Fischer ${ }^{1}$, N. Huret ${ }^{7}$, D. Ionov $^{4}$, M. López-Puertas ${ }^{3}$, \\ G. Maucher ${ }^{1}$, H. Oelhaf ${ }^{1}$, J.-P. Pommereau ${ }^{4}$, R. Ruhnke ${ }^{1}$, M. Sinnhuber ${ }^{2}$, G. Stiller ${ }^{1}$, M. Van Roozendael ${ }^{5}$, and \\ G. Zhang ${ }^{1, *}$
}

${ }^{1}$ Institut für Meteorologie und Klimaforschung (IMK), Forschungszentrum Karlsruhe, Karlsruhe, Germany

${ }^{2}$ Institute of Environmental Physics and Remote Sensing (IUP/IFE), University of Bremen, Bremen, Germany

${ }^{3}$ Instituto de Astrofísica de Andalucía (IAA), Consejo Superior de Investigaciones Cientificas, Granada, Spain

${ }^{4}$ Service d'Aéronomie, CNRS, Verrières-le-Buisson, France

${ }^{5}$ Belgian Institute for Space Aeronomy (IASB-BIRA), Brussels, Belgium

${ }^{6}$ Oxford University, Oxford, UK

${ }^{7}$ Laboratoire de Physique et Chimie de l'Environnement (LPCE), CNRS, Orléans, France

${ }^{8}$ IFAC-CNR, Firenze, Italy

*now at: Shangqiu Normal College, Shangqiu, China

Received: 18 December 2006 - Published in Atmos. Chem. Phys. Discuss.: 2 March 2007

Revised: 15 May 2007 - Accepted: 12 June 2007 - Published: 25 June 2007

\begin{abstract}
The Michelson Interferometer for Passive Atmospheric Sounding (MIPAS) instrument was launched aboard the environmental satellite ENVISAT into its sunsynchronous orbit on 1 March 2002. The short-lived species $\mathrm{NO}_{2}$ is one of the key target products of MIPAS that are operationally retrieved from limb emission spectra measured in the stratosphere and mesosphere. Within the MIPAS validation activities, a large number of independent observations from balloons, satellites and ground-based stations have been compared to European Space Agency (ESA) version 4.61 operational $\mathrm{NO}_{2}$ data comprising the time period from July 2002 until March 2004 where MIPAS measured with full spectral resolution. Comparisons between MIPAS and balloon-borne observations carried out in 2002 and 2003 in the Arctic, at mid-latitudes, and in the tropics show a very good agreement below $40 \mathrm{~km}$ altitude with a mean deviation of roughly $3 \%$, virtually without any significant bias. The comparison to ACE satellite observations exhibits only a small negative bias of MIPAS which appears not to be significant. The independent satellite instruments HALOE, SAGE II, and POAM III confirm in common for the spring-summer time period a negative bias of MIPAS in the Arctic and a positive bias in the Antarctic middle and upper stratosphere exceeding frequently the combined systematic error limits. In contrast to the ESA operational processor, the IMK/IAA retrieval code allows accurate inference of $\mathrm{NO}_{2}$ volume mixing ratios under consideration of all important non-LTE pro-
\end{abstract}

Correspondence to: G. Wetzel

(gerald.wetzel@imk.fzk.de) cesses. Large differences between both retrieval results appear especially at higher altitudes, above about 50 to $55 \mathrm{~km}$. These differences might be explained at least partly by nonLTE under polar winter conditions but not at mid-latitudes. Below this altitude region mean differences between both processors remain within 5\% (during night) and up to $10 \%$ (during day) under undisturbed (September 2002) conditions and up to $40 \%$ under perturbed polar night conditions (February and March 2004). The intercomparison of ground-based NDACC observations shows no significant bias between the FTIR measurements in Kiruna $\left(68^{\circ} \mathrm{N}\right)$ and MIPAS in summer 2003 but larger deviations in autumn and winter. The mean deviation over the whole comparison period remains within $10 \%$. A mean negative bias of $15 \%$ for MIPAS daytime and $8 \%$ for nighttime observations has been determined for UV-vis comparisons over Harestua $\left(60^{\circ} \mathrm{N}\right)$. Results of a pole-to-pole comparison of ground-based DOAS/UV-visible sunrise and MIPAS mid-morning column data has shown that the mean agreement in 2003 falls within the accuracy limit of the comparison method. Altogether, it can be indicated that MIPAS $\mathrm{NO}_{2}$ profiles yield valuable information on the vertical distribution of $\mathrm{NO}_{2}$ in the lower and middle stratosphere (below about $45 \mathrm{~km}$ ) during day and night with an overall accuracy of about $10-20 \%$ and a precision of typically $5-15 \%$ such that the data are useful for scientific studies. In cases where extremely high $\mathrm{NO}_{2}$ occurs in the mesosphere (polar winter) retrieval results in the lower and middle stratosphere are less accurate than under undisturbed atmospheric conditions. 


\section{Introduction}

The abundance of reactive nitrogen and its partitioning plays an important role in the understanding of gas-phase and heterogeneous processes in stratospheric chemistry. The shortlived species nitrogen dioxide $\left(\mathrm{NO}_{2}\right)$ is involved in catalytic cycles leading to the destruction of stratospheric ozone. In addition, $\mathrm{NO}_{2}$ regulates the ozone budget via reactions with radicals to form reservoir species like $\mathrm{HNO}_{3}, \mathrm{ClONO}_{2}$, $\mathrm{BrONO}_{2}$, and $\mathrm{N}_{2} \mathrm{O}_{5}$ which temporarily remove these radicals from fast ozone destroying reactions.

$\mathrm{NO}_{2}$ exhibits a strong diurnal variation in the stratosphere and is in photochemical equilibrium with $\mathrm{NO}$ and $\mathrm{N}_{2} \mathrm{O}_{5}$ (see, e.g. Brasseur and Solomon, 2005). At sunset, NO is rapidly converted to $\mathrm{NO}_{2}$ mainly via the reaction with $\mathrm{O}_{3}$ :

$\mathrm{NO}+\mathrm{O}_{3} \rightarrow \mathrm{NO}_{2}+\mathrm{O}_{2}$

During the night, $\mathrm{NO}_{2}$ is gradually decomposed to form $\mathrm{N}_{2} \mathrm{O}_{5}$ by the following reactions:

$\mathrm{NO}_{2}+\mathrm{O}_{3} \rightarrow \mathrm{NO}_{3}+\mathrm{O}_{2}$

$\mathrm{NO}_{2}+\mathrm{NO}_{3}+M \rightarrow \mathrm{N}_{2} \mathrm{O}_{5}+M$

After sunrise, $\mathrm{N}_{2} \mathrm{O}_{5}$ is photolyzed back into $\mathrm{NO}_{2}$ and $\mathrm{NO}_{3}$ :

$\mathrm{N}_{2} \mathrm{O}_{5}+h v \rightarrow \mathrm{NO}_{2}+\mathrm{NO}_{3}$

It can also be destroyed by collisional decomposition via the reverse reaction of (R3). At the same time, $\mathrm{NO}_{2}$ reacts very rapidly to reform $\mathrm{NO}$ either by photolysis or by reaction with atomic oxygen:

$\mathrm{NO}_{2}+h v \rightarrow \mathrm{NO}+\mathrm{O}\left({ }^{3} P\right)$

$\mathrm{NO}_{2}+\mathrm{O} \rightarrow \mathrm{NO}+\mathrm{O}_{2}$

This diurnal variation of $\mathrm{NO}_{2}$ results in a minimum concentration after sunrise and a maximum concentration shortly after sunset.

Stratospheric $\mathrm{NO}_{2}$ measurements have been carried out since the 1970s from a variety of airborne and ground-based platforms using in-situ and remote sensing techniques (e.g., Noxon et al., 1979; Coffey et al., 1981; Kondo et al., 1985; Roscoe et al., 1986; Pommereau and Goutail, 1988; Webster et al., 1990; Pfeilsticker and Platt, 1994; Chance et al., 1996; Renard et al., 1996; Wetzel et al., 1997; Sen et al., 1998; Payan et al., 1999).

Satellite measurements are essential for monitoring the behaviour and trends of chemical species in the atmosphere since a global set of simultaneously derived atmospheric parameters can be obtained. Early spaceborne observations of $\mathrm{NO}_{2}$ were performed between 1978 and 1979 by the LIMS radiometer (Gille and Russell III, 1984). The Atmospheric Trace Molecule Spectroscopy experiment (ATMOS) has flown four times on the Space Shuttle between 1985 and 1994 measuring $\mathrm{NO}_{2}$ in infrared solar occultation (Russell
III et al., 1988; Newchurch et al., 1996). The families of the Stratospheric Aerosol and Gas Experiment (SAGE I, II, and III; Chu and McCormick, 1986; Cunnold et al., 1991; NASA LaRC, 2006) and Polar Ozone and Aerosol Measurement (POAM II and III; Randall et al., 1998; Randall et al., 2002) observe $\mathrm{NO}_{2}$ by solar occultation in the visible while the Halogen Occultation Experiment (HALOE; Russell III et al., 1993) on the Upper Atmosphere Research Satellite (UARS) spacecraft operated in the infrared spectral domain. On the same platform, $\mathrm{NO}_{2}$ was observed in the infrared by the Improved Stratospheric and Mesospheric Sounder (ISAMS) by means of pressure modulator radiometer technique (Reburn et al., 1996) and by the Cryogenic Limb Array Etalon Spectrometer (CLAES; Dessler et al., 1996). Further satellite sensors measuring $\mathrm{NO}_{2}$ in the infrared spectral region are the two Improved Limb Atmospheric Spectrometers (ILAS I and II; Sasano et al., 1999; Nakajima et al., 2006) and the Atmospheric Chemistry Experiment Fourier Transform Spectrometer (ACE-FTS; Bernath et al., 2005).

The Environmental Satellite (ENVISAT) was launched into its sun-synchronous orbit on 1 March 2002 and operates in an altitude of $800 \mathrm{~km}$. The Scanning Imaging Absorption Spectrometer (SCIAMACHY; Bovensmann et al., 1999) measures $\mathrm{NO}_{2}$ and a number of climate relevant trace gases during day in nadir and limb viewing geometries, as well as in solar and lunar occultation modes (Amekudzi et al., 2005; Bracher et al., 2005; Meyer et al., 2005; Rozanov et al., 2005). The Global Ozone Monitoring by Occultation of Stars (GOMOS; Bertaux et al., 1991) instrument observes $\mathrm{NO}_{2}$ and some other species during twilight and night (Marchand et al., 2004). The Michelson Interferometer for Passive Atmospheric Sounding (MIPAS; Fischer and Oelhaf, 1996; Fischer et al., 2007 ${ }^{1}$ ) is one of the three chemistry instruments aboard ENVISAT. MIPAS operates in the mid-infrared spectral region with high spectral resolution measuring many climate relevant species within the nitrogen, chlorine and hydrogen chemical families together with tropospheric source gases simultaneously. Increasing complexity of such space instruments and enhanced diversity of products expected from instruments like MIPAS demand for even increased efforts in validation. Apart from satellite measurements, balloon-borne observations are a very useful tool to obtain distributions of a large number of molecules with sufficiently high vertical resolution. However, due to large logistical efforts the number of these flights is very limited. This holds also for aircraft measurements which may cover larger horizontal regions compared to balloons

\footnotetext{
${ }^{1}$ Fischer, H., Birk, M., Blom, C., Carli, B., Carlotti, M., von Clarmann, T., Delbouille, L., Dudhia, A., Ehhalt, D., Endemann, M., Flaud, J.-M., Gessner, R., Kleinert, A., Koopmann, R., Langen, J., López-Puertas, M., Mosner, P., Nett, H., Oelhaf, H., Perron, G., Remedios, J., Ridolfi, M., Stiller, G., and Zander, R.: MIPAS: An instrument for atmospheric and climate research, Atmos. Chem. Phys. Discuss., submitted, 2007.
} 
but from distinctly lower flight altitudes. Ground-based measurements can be carried out all over the year but, apart from LIDAR observations, the vertical resolution is generally very low. The use of independent satellite measurements to validate trace gas products has the great advantage that global coverage for all seasons is available and that validation activities are not limited to a certain period and location. This paper outlines the results of the MIPAS validation activities concerning the molecule $\mathrm{NO}_{2}$. The comparisons were made with the European Space Agency (ESA) operational version 4.61 data comprising the time period from July 2002 until March 2004 where MIPAS measured with full spectral resolution.

\section{MIPAS $\mathrm{NO}_{2}$ data}

The limb viewing Fourier transform spectrometer MIPAS on ENVISAT (MIPAS-E) operates in the mid-infrared spectral region covering five spectral bands within $685 \mathrm{~cm}^{-1}$ and $2410 \mathrm{~cm}^{-1}$ with an unapodized full spectral resolution of $0.035 \mathrm{~cm}^{-1}$ (Fischer and Oelhaf, 1996; Fischer et al., 2007 ${ }^{1}$ ). Owing to its sun-synchronous orbit $\left(98.55^{\circ}\right.$ inclination) in about $800 \mathrm{~km}$, MIPAS passes the equator in southwards direction at 10:00 am local time 14.3 times a day. During each orbit approximately 72 limb scans (full resolution mode) are recorded covering tangent altitudes from 8 to $68 \mathrm{~km}$ in steps of $3 \mathrm{~km}$. The vertical resolution is about $3 \mathrm{~km}$ coinciding with the vertical field of view (FOV) of $3 \mathrm{~km}$ while the horizontal field of view extends to $30 \mathrm{~km}$. Level 1B and level 2 processing of the data (version 4.61) including all processing steps from raw data to calibrated spectra and volume mixing ratio (VMR) profiles of species has been performed by ESA using the operational retrieval algorithm described by Raspollini et al. (2006) and references therein. Calibrated spectra are analyzed using a global fit approach (Carlotti, 1988) by varying the input parameters of the forward model according to a non-linear Gauss-Newton procedure. In a first step, temperature and pressures at the tangent altitudes are retrieved simultaneously ( $p, T$ retrieval), then the VMR profiles of the primary target species $\mathrm{O}_{3}, \mathrm{H}_{2} \mathrm{O}, \mathrm{CH}_{4}, \mathrm{~N}_{2} \mathrm{O}$, $\mathrm{HNO}_{3}$ and $\mathrm{NO}_{2}$ are retrieved individually in sequence.

The $\mathrm{NO}_{2}$ operational analysis of the version 4.61 data has been performed in three microwindows of the $v_{3}$ band near $6.2 \mu \mathrm{m}\left(1615 \mathrm{~cm}^{-1}\right)$. A random error due to the propagation of instrument noise through the retrieval can be extracted from the diagonal elements of the error variance covariance matrix calculated during the retrieval process. Systematic error sources are calculated for day and night conditions and different seasons. The following systematic errors have been taken into account: pressure-temperature random retrieval errors; spectroscopic data errors due to uncertainties in the intensity, width and position of emission lines; radiometric gain, instrumental line shape and spectral calibration inaccuracies; uncertainties in assumed profiles of the contami- nant species $\mathrm{H}_{2} \mathrm{O}$ and $\mathrm{CH}_{4}$; horizontal gradient effects due to assuming a horizontally homogeneous atmosphere for each profile; and errors due to the effects of non local thermodynamic equilibrium (non-LTE). For most cases and at most altitudes in the stratosphere, the random error is the dominant error source with a magnitude of roughly $10 \%$. However, in the upper stratosphere and mesosphere, the systematic non local thermodynamic equilibrium (non-LTE) error gets very important, especially under winter conditions. The total error is calculated as the root sum square of systematic and random components. A detailed discussion of all error components together with their magnitudes is given in Raspollini et al. (2006).

\section{Intercomparison results}

In this section, profiles and vertical column amounts of $\mathrm{NO}_{2}$ measured by several instruments are compared to MIPAS version $4.61 \mathrm{NO}_{2}$ data. A comprehensive study concerning validation methods and strategies is given by von Clarmann (2006) and references therein. Differences in VMR profiles of measured quantities are expressed as either relative or absolute differences. The mean relative difference of several profiles is calculated by dividing the mean absolute difference by the mean profile value of the validation instrument for all coincident altitudes. Differences are displayed together with the combined errors $\sigma_{\text {comb }}$ of both instruments which are defined as:

$\sigma_{\mathrm{comb}}=\sqrt{\sigma_{M}^{2}+\sigma_{I}^{2}}$,

where $\sigma_{M}$ and $\sigma_{I}$ are the precision, systematic or total errors of MIPAS and the validation instrument, respectively. Precision errors (which characterize the reproducibility of a measurement) correspond, in general, to random noise errors, while other error sources are treated as systematic. It should be mentioned that not all systematic error sources (as specified in Sect. 2) could be characterized for all validation instruments. However, dominant error sources (e.g. temperature profile errors) have been included. For statistical comparisons, errors of the temperature profile used for the $\mathrm{NO}_{2}$ retrievals behave more randomly and are therefore included in the precision (random) part of the error budget. The uncertainty of the calculated mean difference (standard error of the mean, SEM) is given by $\sigma / N^{0.5}$ where $\sigma$ is the standard deviation (SD) and $N$ the number of compared observations. The comparison between the standard deviation of the mean difference and the combined random error helps to validate the precision of MIPAS. The comparison between the mean VMR difference and the combined systematic error of the two instruments is appropriate to identify unexplained biases in MIPAS $\mathrm{NO}_{2}$ observations which turn out to be significant when they exceed the combined systematic error limits.

As mentioned in Sect. $1, \mathrm{NO}_{2}$ volume mixing ratios exhibit a strong diurnal variation. Changes in the volume 
Table 1. Overview on balloon flights for the validation of MIPAS-E. Distances between MIPAS-E and the validation instrument refer to an altitude of $30 \mathrm{~km}$. Concerning MIPAS-B, distances refer to direct coincidences with MIPAS-E overpasses and 2-day trajectory calculations (in parenthesis).

\begin{tabular}{|c|c|c|c|c|}
\hline Location & Date & Instrument & Distance (at $30 \mathrm{~km}$ ) & Time difference \\
\hline Kiruna & 21 Jan 2003 & SPIRALE & $623 \mathrm{~km}$ & $81 \mathrm{~min}$ \\
\hline \multirow{3}{*}{ (Sweden, $68^{\circ} \mathrm{N}$ ) } & 20/21 March 2003 & MIPAS-B & $<241 \mathrm{~km}(500 \mathrm{~km})$ & $\leq 20 \min (1 \mathrm{~h})$ \\
\hline & 30 March 2003 & SAOZ & $<700 \mathrm{~km}$ & $\leq 3$ days \\
\hline & 3 July 2003 & MIPAS-B & $9 \mathrm{~km}(500 \mathrm{~km})$ & $507 \mathrm{~min}(1 \mathrm{~h})$ \\
\hline Vanscoy & 3 Sep 2003 & SAOZ & $<700 \mathrm{~km}$ & $\leq 3$ days \\
\hline$\left(\right.$ Canada, $\left.54^{\circ} \mathrm{N}\right)$ & 4 Sep 2003 & SAOZ & $<700 \mathrm{~km}$ & $\leq 3$ days \\
\hline Aire sur l'Adour & 24 Sep 2002 & MIPAS-B & $<147 \mathrm{~km}(500 \mathrm{~km})$ & $\leq 16 \min (1 \mathrm{~h})$ \\
\hline$\left(\right.$ France, $\left.44^{\circ} \mathrm{N}\right)$ & 02 Oct 2003 & SPIRALE & $401 \mathrm{~km}$ & 4.5 days \\
\hline Bauru & 18 Feb 2003 & SAOZ & $<700 \mathrm{~km}$ & $\leq 3$ days \\
\hline$\left(\right.$ Brazil, $\left.23^{\circ} \mathrm{S}\right)$ & 23 Feb 2003 & SAOZ & $<700 \mathrm{~km}$ & $\leq 3$ days \\
\hline
\end{tabular}

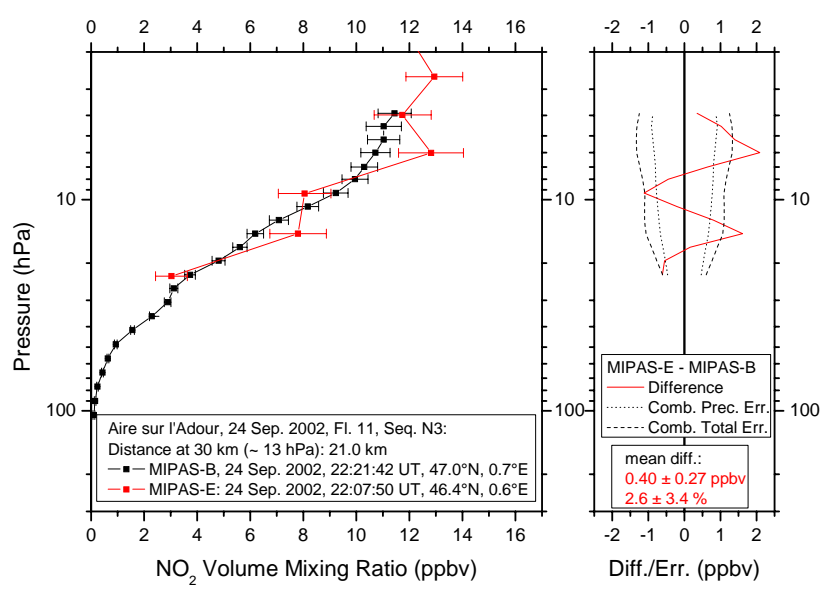

Fig. 1. Direct comparison of $\mathrm{NO}_{2}$ profiles measured by MIPASB (flight no. 11, sequence N3) and MIPAS-E (orbit 2975) on 24 September 2002 above southern France together with difference and combined errors $(1 \sigma)$. The mean difference value is calculated over all coincident altitudes.

mixing ratio may reach several ppbv within half an hour around sunrise and sunset. Consequently, photochemical corrections have been applied to account for temporal and in some cases also spatial differences between MIPAS and the validation instrument.

\subsection{Intercomparison of balloon-borne observations}

As part of the validation program of the chemistry instruments aboard ENVISAT a number of balloon flights were carried out within dedicated campaigns. An overview of all balloon flights used within this comparison study is given in Table 1. A total of three validation flights were carried out with the cryogenic Fourier transform infrared spectrometer MIPAS-B, the balloon-borne version of MIPAS, from
Aire sur l'Adour (France, $44^{\circ} \mathrm{N}$ ) on 24 September 2002, Kiruna (Sweden, $68^{\circ}$ N) on 20/21 March 2003, and again from Kiruna on 3 July 2003. MIPAS-B measures all atmospheric parameters covered by MIPAS-E. Essential for the balloon instrument is the sophisticated line of sight stabilization system, which is based on an inertial navigation system and supplemented with an additional star reference system. Averaging several spectra during one single elevation angle yields to a reduction of the noise equivalent spectral radiance (NESR) and therefore to an improvement of the signal to noise ratio. The MIPAS-B data processing including instrument characterization is described in Friedl-Vallon et al. (2004) and references therein. Retrieval calculations of atmospheric target parameters were performed with a least squares fitting algorithm using analytical derivative spectra calculated by the Karlsruhe Optimized and Precise Radiative transfer Algorithm (KOPRA; Stiller et al., 2002; Höpfner et al., 2002). A Tikhonov-Phillips regularization approach constraining with respect to the form of an a priori profile was adopted. The resulting vertical resolution lies typically between 2 and $3 \mathrm{~km}$ and is therefore comparable to the vertical resolution of MIPAS-E. $\mathrm{NO}_{2}$ was analyzed in MIPASB proven microwindows in the $v_{3}$ band between $1585 \mathrm{~cm}^{-1}$ and $1615 \mathrm{~cm}^{-1}$. Spectroscopic parameters chosen for the MIPAS-B retrieval are consistent with the database taken for the MIPAS-E data analysis (Flaud et al., 2003) and originate mainly from the HITRAN 2004 database (Rothman et al., 2005). A further overview on the MIPAS-B data analysis is given in Wetzel et al. (2006) and references therein.

Figure 1 shows an example for perfect coincidence between MIPAS-B and MIPAS-E on 24 September 2002 above southern France. The mean distance of both observations in the compared altitude region was about $57 \mathrm{~km}$ and the mean time difference was only $14 \mathrm{~min}$. The MIPAS-E profile shows some retrieval instabilities which occur quite frequently in the ESA operational data. Apart from these 


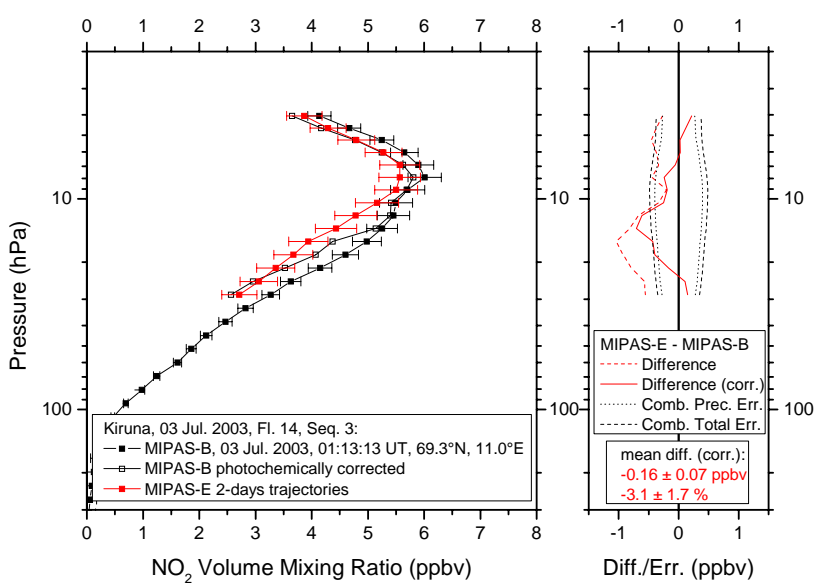

Fig. 2. Trajectory comparison for the MIPAS-B flight carried out from Kiruna on 3 July 2003. The MIPAS-B $\mathrm{NO}_{2}$ values have been transferred to the time and location of the individual MIPAS-E observations with the help of KASIMA model calculations. The mean 2-day trajectory MIPAS-E profile (consisting of several averaged coinciding profiles) can then be compared to the accordingly corrected MIPAS-B profile. The mean difference value is calculated over all coincident altitudes.

instabilities, the MIPAS-B profiles are fairly well reproduced by MIPAS-E and differences are mostly within the combined errors. A small positive bias of $0.4 \mathrm{ppbv}$, more pronounced at higher altitudes, can be recognized in the satellite data.

To increase the number of matches between MIPAS-B and MIPAS-E, trajectory calculations have been performed at the FU (Freie Universität) Berlin (K. Grunow, private communication, 2005). The trajectory model (Langematz et al., 1987; Reimer and Kaupp, 1997) uses operational analyses and forecasts of the European Centre for Medium-Range Weather Forecasts $(\mathrm{ECMWF})$ on a $2.5^{\circ} \times 2.5^{\circ}$ latitude/longitude grid. The trajectories are calculated on 25 isentropic levels from the surface up to $1600 \mathrm{~K}$ with interpolation between these levels. For this study forward and backward trajectories up to two days were calculated, starting on the MIPAS-B tangent point locations. MIPAS-E measurement points have been searched within a match criterion of not more than an hour in time and less than $500 \mathrm{~km}$ horizontal distance to the centre of the satellite scan.

To balance temporal and spatial differences of the observations of both sensors, simulations have been carried out with the three-dimensional Chemistry Transport Model (CTM) KASIMA (Karlsruhe Simulation model of the Middle Atmosphere; Kouker et al., 1999) which was run in a $5.6^{\circ} \times 5.6^{\circ}$ horizontal resolution. MIPAS-B $\mathrm{NO}_{2}$ values were corrected by scaling them with the altitude-dependent $\mathrm{NO}_{2}$ ratio determined from the modelled $\mathrm{NO}_{2}$ profiles for the MIPAS-B and MIPAS-E measurement times and locations.

Figure 2 displays an example for the trajectory comparison for the balloon flight on 3 July 2003 which was carried out from Kiruna. Dependent on altitude, a total of 5 to 7 trajec-

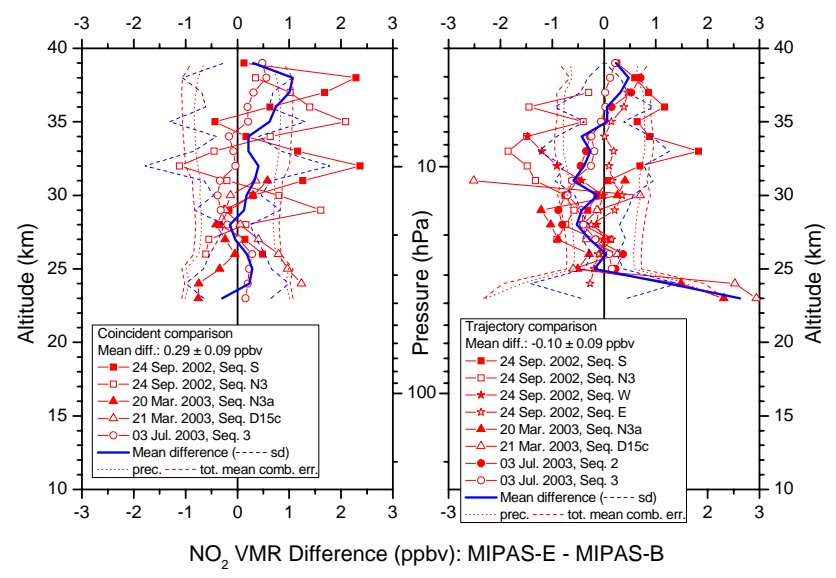

Fig. 3. Differences of all coincident (left) and trajectory (right) comparisons between MIPAS-B and MIPAS-E including combined errors and standard deviation. A photochemical correction has been applied for all trajectory comparisons and the coincident comparison on 3 July 2003, where only a coincidence in space but not in time could be achieved. No photochemical correction was necessary for the other coincident cases since temporal differences are less than $33 \mathrm{~min}$ and spatial differences are less than $250 \mathrm{~km}$ in all altitudes and since the observations were not taken during sunrise and sunset conditions where $\mathrm{NO}_{2}$ changes rapidly with time. A mean difference value is calculated over all coincident altitudes.

tory matches have been averaged by taking into account the individual random error to yield a mean MIPAS-E profile. The graph shows, that the bias between the measured profiles of both sensors vanishes at many altitudes when comparing the photochemically corrected MIPAS-B profile to the mean satellite profile.

A summary of all MIPAS balloon comparisons is depicted in Fig. 3. A mean positive bias of 0.29 ppbv (4.2\%) is visible in the coincidence case, especially for altitudes above about $28 \mathrm{~km}(18 \mathrm{hPa})$. The mean difference lies clearly within the combined total error and, except a small region around $38 \mathrm{~km}$, even within the combined precision error. The trajectory comparison, however, reveals a small negative bias between 25 and $35 \mathrm{~km}$ altitude while, below and above, MIPAS-E tends to higher $\mathrm{NO}_{2}$ values compared to the balloon instrument. The mean deviation over all altitudes is $-0.10 \mathrm{ppbv}(-2.2 \%)$. The combined coincidence and trajectory comparison results in a small mean deviation of $0.21 \mathrm{ppbv}(3.8 \%)$ between MIPAS-E and MIPAS-B measured $\mathrm{NO}_{2}$ values.

The tunable diode laser instrument SPIRALE (Spectromètre Infra Rouge pour l'étude de l'Atmosphère par diodes Laser Embarquées) is a balloon-borne instrument for the in situ measurement of stratospheric trace species. 86 reflections of six laser beams in a $3.5 \mathrm{~m}$ multipass Herriott cell exposed to ambient air above the tropopause lead to a $300 \mathrm{~m}$ optical path length. Species concentrations are retrieved from direct absorption in the mid-infrared spectral 


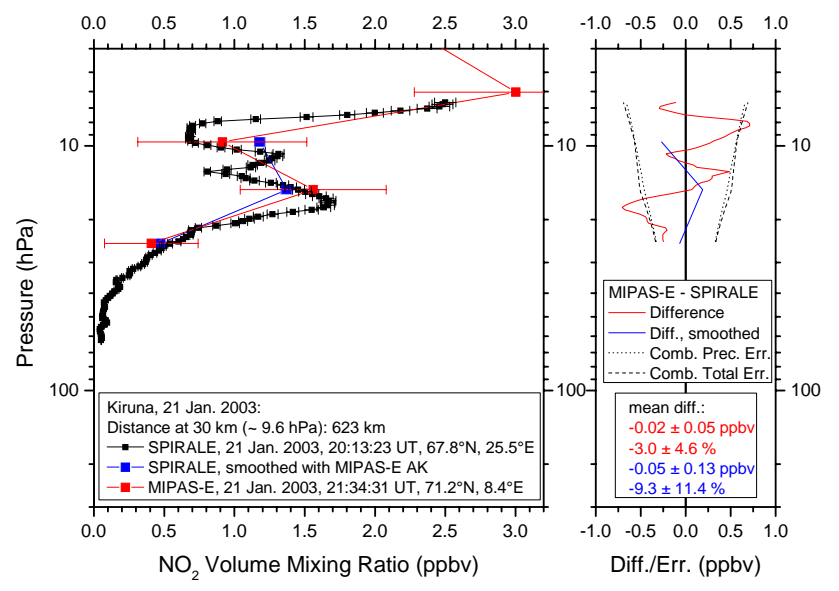

Fig. 4. Comparison of $\mathrm{NO}_{2}$ profiles measured by SPIRALE and MIPAS-E (orbit 4678) on 21 January 2003. The highly resolved vertical profile of SPIRALE has been smoothed with the MIPAS-E averaging kernel matrix.

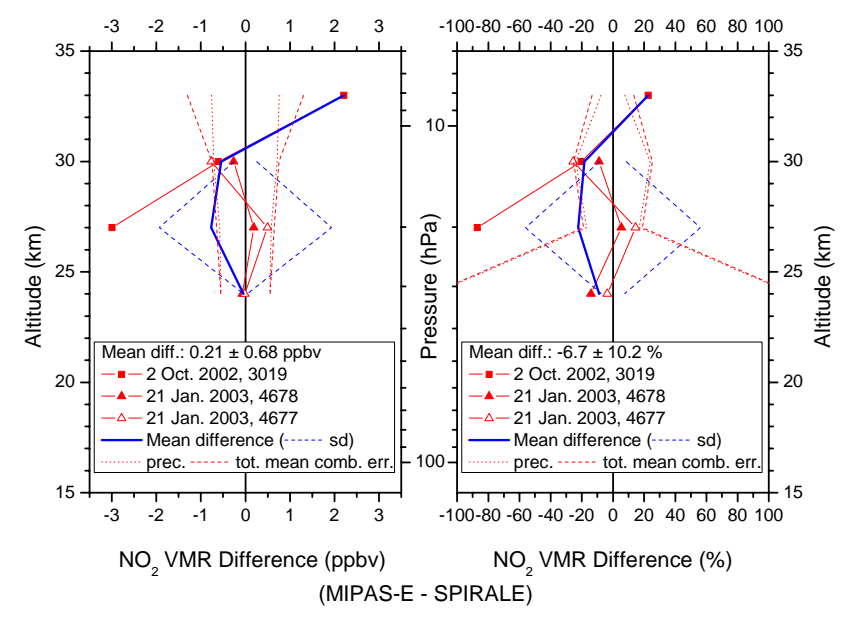

Fig. 5. Differences of all comparisons between SPIRALE and MIPAS-E. An ascent profile of SPIRALE from 2 October 2002 is compared to a MIPAS-E limb scan performed during orbit 3019. The SPIRALE profile from 21 January 2003 has been compared to MIPAS-E observations carried out during orbits 4677 and 4678.

region by fitting experimental spectra and spectra calculated using spectroscopic parameters of absorption lines from the HITRAN database (Rothman et al., 2005). With this technique concentrations of $\mathrm{CH}_{4}, \mathrm{~N}_{2} \mathrm{O}, \mathrm{NO}_{2}, \mathrm{HNO}_{3}, \mathrm{HCl}, \mathrm{CO}$ and $\mathrm{O}_{3}$ can be observed simultaneously. A detailed description of the instrument and of its operating modes can be found in Moreau et al. (2005). Validation flights were carried out from Aire sur l'Adour on 2 October 2002 and from Kiruna on 21 January 2003.

An example for a SPIRALE comparison with MIPAS-E is given in Fig. 4 for the arctic flight on 21 January 2003. The SPIRALE profile has been smoothed with the averaging ker-

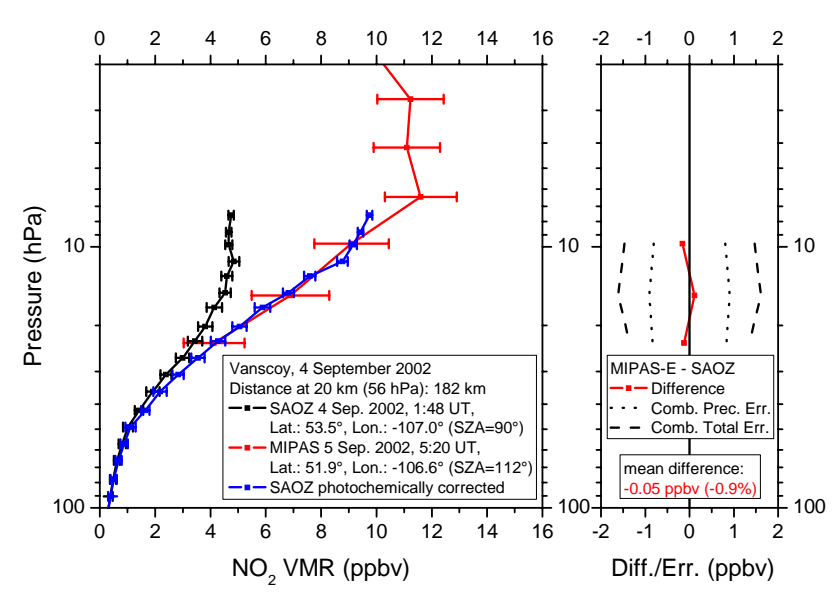

Fig. 6. Comparison of $\mathrm{SAOZ}$ and MIPAS $\mathrm{NO}_{2}$ measurements above Vanscoy (Canada, $54^{\circ} \mathrm{N}$ ) on 4 September 2002. The SAOZ sunset observations were photochemically corrected to fit the MIPAS nighttime measurements.

nel of MIPAS according to the method described in Rodgers (2000). Both measurements were performed inside the polar vortex. Mean differences are small with $-0.05 \mathrm{ppbv}(-9.3 \%)$ in the smoothed case.

Figure 5 shows all SPIRALE comparisons with MIPAS-E. Mean differences in potential vorticity (PV) are less than $8 \%$ for the January flight between 24 and $30 \mathrm{~km}$ altitude. For the 2 October 2002 flight no MIPAS-E data for a coincident comparison is available. Hence, backward trajectories ending at the location of the SPIRALE profiles $\left(44^{\circ} \mathrm{N}, 0^{\circ} \mathrm{E}\right)$ on $2 \mathrm{Oc}-$ tober 2002 (07:15-08:30 UT at ascent) have been computed as a function of potential temperature in $25 \mathrm{~K}$ steps (about $1 \mathrm{~km}$ ). Profiles 14 and 15 of orbit 3019 have been proven to be the best matches for comparison with SPIRALE. These profiles were measured close to $00 \mathrm{UT}$ near $42^{\circ} \mathrm{N}$ and $46^{\circ} \mathrm{N}$ on 28 September, 4.5 days before the SPIRALE flight. A correction for the diurnal variation of $\mathrm{NO}_{2}$ has been applied to the smoothed SPIRALE profiles with the help of a photochemical model. For the highest altitude (around $33 \mathrm{~km}$ ) MIPAS-E overestimates the SPIRALE observations, while below a tendency of underestimation of the $\mathrm{NO}_{2}$ values, especially in the non-coincident October 2002 case, is obvious.

The balloon-borne diode array UV-visible spectrometer SAOZ (Système d'Analyse par Observation Zénitale) measures vertical profiles of $\mathrm{O}_{3}$ and $\mathrm{NO}_{2}$ (Pommereau and Piquard, 1994). A Global Positioning System (GPS) and an accurate pressure and temperature sensor (PTU) are attached to the gondola reaching a flight altitude of typically $30 \mathrm{~km}$. Solar occultation measurements are performed during the ascent of the balloon and during sunset from float or during sunrise and descent of the balloon. Slant columns of measured species along the line of sight are retrieved by the DOAS technique (Differential Optical Absorption Spectroscopy). Vertical profiles are deduced using a linear 

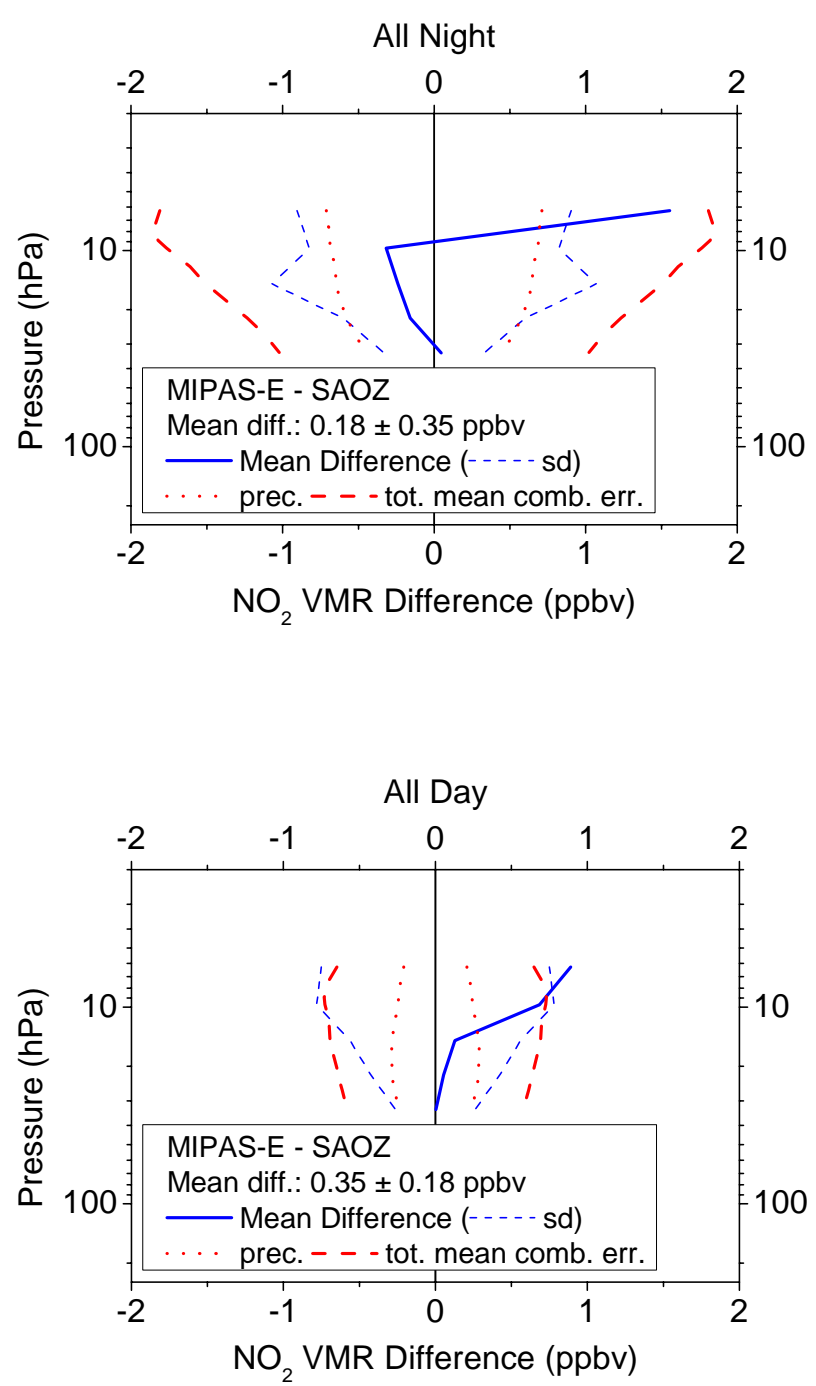

Fig. 7. $\mathrm{NO}_{2}$ measured differences between MIPAS and SAOZ for all MIPAS night (top panel) and MIPAS day (bottom panel) comparisons.

onion peeling inversion procedure after calculating the tangent height from GPS. Since the full solar disk is observed, the vertical resolution of the profile is $1.4 \mathrm{~km}$. A chemical box model is included for taking into account the $\mathrm{NO}_{2}$ variations during twilight as a function of solar zenith angle (SZA) and altitude. A comprehensive description of the data analysis is given in Denis et al. (2005). Fifteen flights have been carried out since the launch of ENVISAT, namely three in the Arctic (Kiruna, August 2002 until March 2003), eight at mid-latitudes (Vanscoy, Canada, 54 ${ }^{\circ}$ N, September 2002 and August 2004, Aire sur l'Adour, France, $44^{\circ}$ N, May 2002 until October 2005), and four in the tropics (Bauru, Brazil, $23^{\circ} \mathrm{S}$, February 2003 and February 2004). Flights and direct coincidence criteria used for this validation study are listed in Table 1.

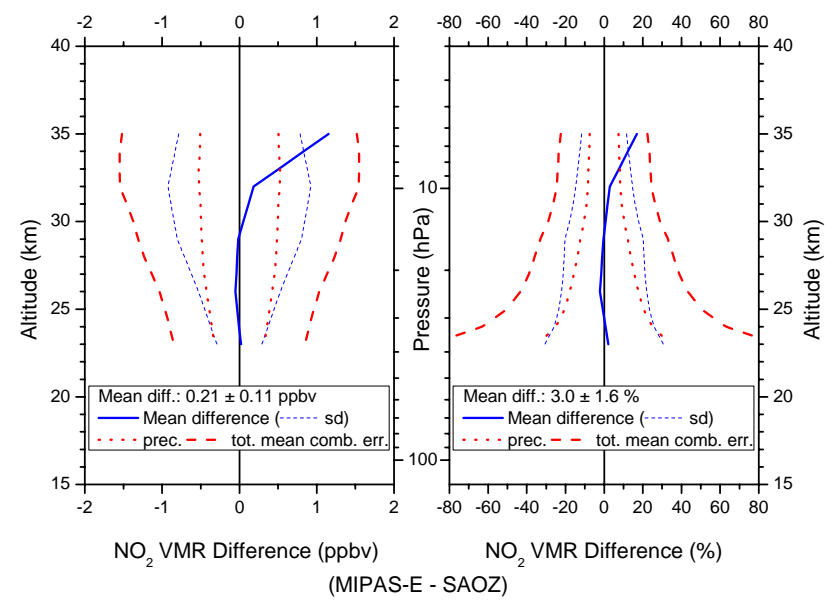

Fig. 8. Differences of all comparisons between MIPAS and SAOZ.

An example for a comparison between SAOZ and MIPAS for the flight from Vanscoy on 4 September 2002 is shown in Fig. 6. Correcting the SAOZ data with a photochemical model yields a close to perfect agreement with MIPAS for this comparison with a mean difference of less than $1 \%$ between about 10 and $23 \mathrm{hPa}$ (about 32 to $25 \mathrm{~km}$ ). Figure 7 shows that there is in general a good agreement for the nighttime comparisons up to about $10 \mathrm{hPa}$ while above MIPAS $\mathrm{NO}_{2}$ mixing ratios are too high compared to the $\mathrm{SAOZ}$ observations. A positive bias is also visible in the daytime comparison (see Fig. 7) at higher altitudes. Differences of all comparisons are depicted in Fig. 8. Except the region above about $30 \mathrm{~km}$ where MIPAS exhibits a positive bias, differences between MIPAS and SAOZ are very small with a mean deviation over the complete altitude range of $0.21 \mathrm{ppbv}$ $(3.0 \%)$.

A summary of the comparison of all balloon flights is given in Fig. 9. A mean difference profile was calculated taking into account the number of coincident measurement sequences. Below about $31 \mathrm{~km}$, the mean difference of all intercomparisons is well inside the combined errors. However, above this altitude region, an increasing positive bias of MIPAS-E is visible reaching a magnitude of up to $0.77 \mathrm{ppbv}$ (9.9\%) exceeding slightly the systematic error limits at $38 \mathrm{~km}$. The mean deviation over all altitudes between 23 and $39 \mathrm{~km}$ is found to be only $0.25 \mathrm{ppbv}(3.2 \%)$. Hence the general agreement between balloon-borne observations and MIPAS-E is found to be very good.

\subsection{Intercomparison of satellite observations}

Satellite observations are very useful for validation of other spaceborne sensors since the number of possible coincidences is large and potential systematic differences appear to be very meaningful due to enhanced statistics. In the following sections intercomparison results of different satellite sensors are being discussed. A common strategy was adapted 


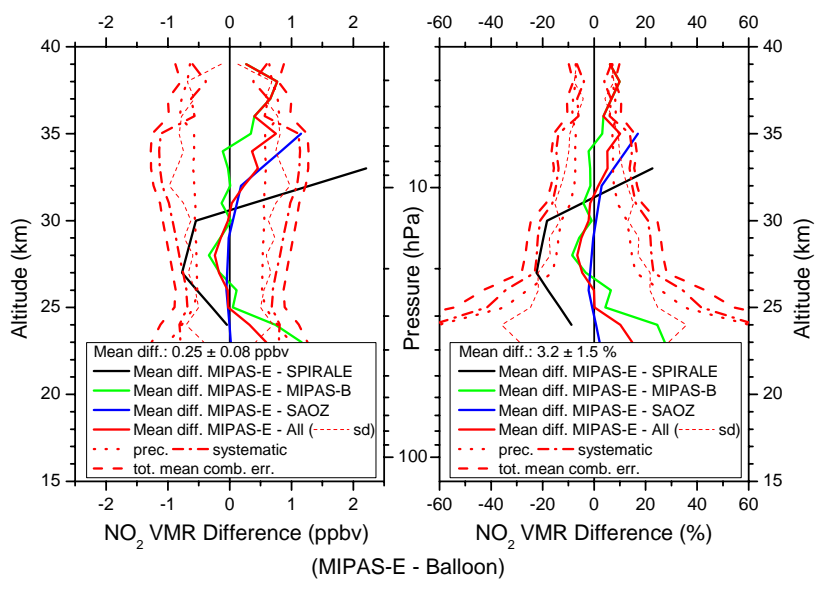

Fig. 9. Differences of all comparisons between MIPAS-E and balloon-borne observations of different instruments together with mean combined precision, systematic, and total errors.

for the validation of MIPAS $\mathrm{NO}_{2}$ profiles by intercomparison with these space-borne sensors, using concepts for statistical bias and precision determination with matching pairs of measurements as described in von Clarmann (2006). Unless otherwise noted, a standard collocation criterion for maximum space and time separation of $300 \mathrm{~km}$ and $3 \mathrm{~h}$ between MIPAS and the reference measurement has been applied to select the VMR comparison pairs. For each of the selected pairs, both MIPAS and the reference instrument $\mathrm{NO}_{2}$ profiles were interpolated to a mean pressure grid over all collocated MIPAS measurements.

\subsubsection{HALOE comparison}

The Halogen Occultation Experiment (HALOE) was launched in September 1991 on board the Upper Atmosphere Research Satellite (UARS) and operated until November 2005. The experiment uses solar occultation in several infrared channels and has recorded trace gas and temperature profiles of the middle atmosphere since October 1991. The $\mathrm{NO}_{2}$ data is corrected by taking into account variations of the solar zenith angle (SZA) along the line of sight since during day, the partitioning between $\mathrm{NO}, \mathrm{NO}_{2}$, and $\mathrm{N}_{2} \mathrm{O}_{5}$ depends strongly on SZA due to the rapid photolysis of $\mathrm{NO}_{2}$ and the slower photolysis of $\mathrm{N}_{2} \mathrm{O}_{5}$. In this study the HALOE $\mathrm{NO}_{2}$ data version 19 is compared to MIPAS. The validation of previous version 17 data (Gordley et al., 1996) shows mean differences with correlative measurements of about 10 to $15 \%$ over the middle stratosphere. Randall et al. (2002) compared HALOE version $19 \mathrm{NO}_{2}$ with $\mathrm{NO}_{2}$ profiles derived by the Atmospheric Trace Molecule Spectroscopy Experiment (ATMOS). Above $25 \mathrm{~km}$ the two instruments agree within about $10 \%$. The data accuracy of ATMOS is estimated to about $6 \%$ in the altitude region between 15 and $48 \mathrm{~km}$ (Abrams et al., 1996). Since HALOE and MIPAS measured at different so-

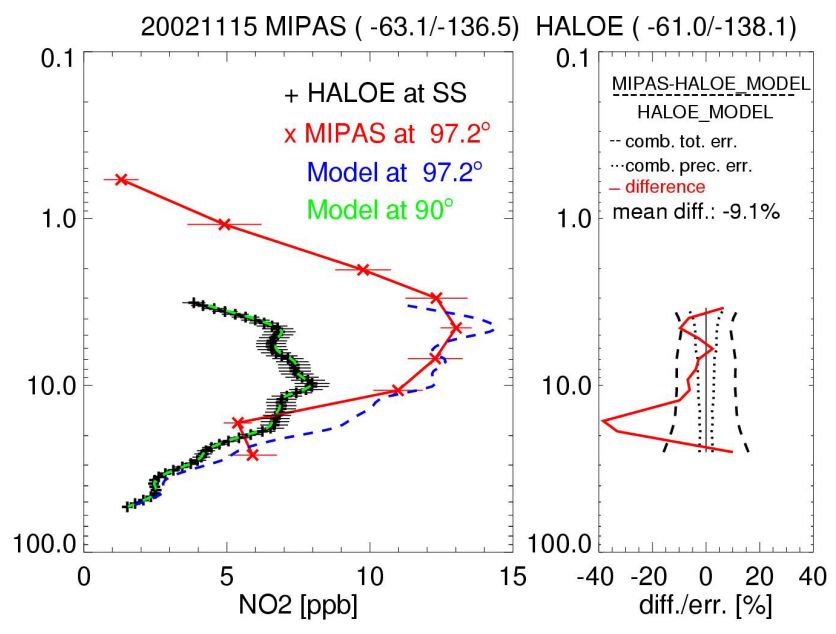

Fig. 10. HALOE and MIPAS comparison in the southern hemisphere (Antarctic region) on 15 November 2002. HALOE measured in occultation during sunset (SS) while MIPAS observed $\mathrm{NO}_{2}$ at the beginning of the night $\left(\mathrm{SZA}=97.2^{\circ}\right)$. The 1 -dimensional model fits the HALOE measurement at $90^{\circ}$ SZA (green and black line). The blue line is the model output for the MIPAS SZA which compares quite well to the MIPAS observation (red line). The difference exceeds the combined total errors near $15 \mathrm{hPa}$ pressure altitude.

lar zenith angles a photochemical correction has been applied using a 1-dimensional photochemical model. This model is initialised with the output of a global 2-dimensional chemistry transport model for the geolocation and day of the measurement. The solar occultation measurements of HALOE have been scaled to the MIPAS SZA by means of the photochemical model calculations (for details, see Bracher et al., 2005). An example for such a comparison is displayed in Fig. 10. Since the altitude resolutions of HALOE and MIPAS are comparable, no smoothing with averaging kernels has been applied. Differences between both sensors are shown in Tables 2 and 3. Figure 11 displays differences between MIPAS and HALOE as a function of latitude. In the southern hemisphere (mid-latitudes and Antarctic) and in northern hemisphere mid-latitudes, MIPAS exhibits a positive bias to HALOE in all altitude regions. Above about $10 \mathrm{hPa}$ pressure altitude this bias amounts roughly $10 \%$ or less which is close to the combined systematic error limit. For lower altitudes at mid-latitudes, the bias between both sensors is significant. In the Antarctic, however, the agreement between MIPAS and HALOE is also quite good at lower altitudes with only a small positive bias in the MIPAS data. In contrast, the arctic comparison shows a negative bias for MIPAS which is significant below about $10 \mathrm{hPa}$. In general the agreement in polar latitudes is better than in mid-latitudes where the solar zenith angle distribution is more variable than in polar regions. 
Table 2. Statistics of the comparison (MIPAS-HALOE)/HALOE $\mathrm{NO}_{2}$ profiles as a function of the solar zenith angle (SZA). Statistical results are given for different pressure altitudes (press. alt.) and only matches within the same air mass are included; mean relative difference (MRD), standard deviation (SD), number of collocations within the SZA range $(\mathrm{N})$ are shown, too.

\begin{tabular}{llllll}
\hline SZA & Press. alt. & MRD & SD & N & Month of year \\
\hline $50^{\circ}-75^{\circ}$ & $8-3.1 \mathrm{hPa}$ & 9 to $11 \%$ & $25-29 \%$ & 83 & Nov-Jan 03, Nov-Feb 04 \\
$75^{\circ}-89^{\circ}$ & $36-4.4 \mathrm{hPa}$ & -24 to 0\% & $5-9 \%$ & 22 & Jan 03/04, May 03, July+Aug 02/03 \\
$89^{\circ}-91^{\circ}$ & $20-3.4 \mathrm{hPa}$ & -10 to $2 \%$ & $5-17 \%$ & 53 & Jan 03/04, Feb 03, Nov 03 \\
$91^{\circ}-101^{\circ}$ & $27-3.5 \mathrm{hPa}$ & -10 to $7 \%$ & $18-27 \%$ & 102 & April + May 03, July 02/03 \\
All & $27-3.5 \mathrm{hPa}$ & 2 to $5 \%$ & $20-48 \%$ & 260 & \\
\hline
\end{tabular}

Table 3. Statistics of the comparison (MIPAS-HALOE)/HALOE $\mathrm{NO}_{2}$ profiles for different latitudinal regions (zone). Statistical results are given for different pressure altitudes (press. alt.) and only matches within the same air mass are included; mean relative difference (MRD), standard deviation (SD), number of collocations within the SZA range (N) are shown, too.

\begin{tabular}{llllll}
\hline Zone & Press. alt. & MRD & SD & N & Month of year \\
\hline $63^{\circ} \mathrm{S}-74^{\circ} \mathrm{S}$ & $17-3.5 \mathrm{hPa}$ & 3 to $13 \%$ & $14-28 \%$ & 106 & Jan 03, Nov 02/03, Dec 03 \\
$28^{\circ} \mathrm{S}-60^{\circ} \mathrm{S}$ & $8-2.5 \mathrm{hPa}$ & 8 to $16 \%$ & $25-30 \%$ & 34 & Jan 03, May 03, July+Aug 02/03 \\
$30^{\circ} \mathrm{N}-52^{\circ} \mathrm{N}$ & $12-3.2 \mathrm{hPa}$ & 5 to $26 \%$ & $11-53 \%$ & 53 & Jan 03/04, Feb 03, Nov 03 \\
$60^{\circ} \mathrm{N}-70^{\circ} \mathrm{N}$ & $32-4.3 \mathrm{hPa}$ & -24 to $-2 \%$ & $9-14 \%$ & 67 & June 03, July 02/03 \\
\hline
\end{tabular}
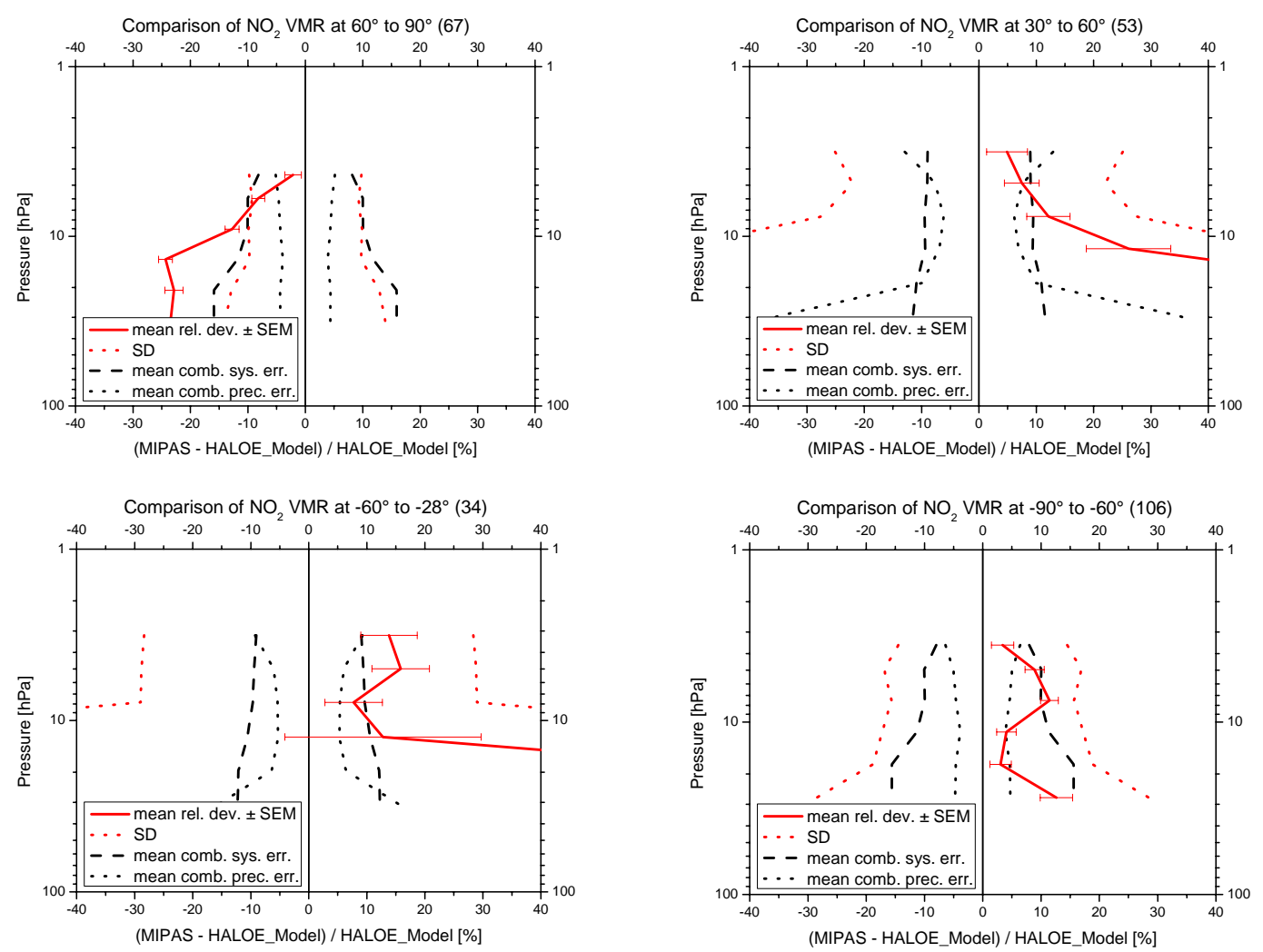

Fig. 11. Mean relative differences (including the standard error of the mean, SEM) between MIPAS and HALOE for different latitude regions in the northern hemisphere (top) and the southern hemisphere (bottom). Standard deviation (SD) and mean combined precision and systematic errors are plotted, too. 
Table 4. Statistics of the comparison (MIPAS-SAGE II)/SAGE II $\mathrm{NO}_{2}$ profiles as a function of the solar zenith angle (SZA). Statistical results are given for different pressure altitudes (press. alt.) and only matches within the same air mass are included; mean relative difference (MRD), standard deviation (SD), number of collocations within the SZA range $(\mathrm{N})$ are shown, too.

\begin{tabular}{llllll}
\hline SZA & Press. alt. & MRD & SD & N & Month of year \\
\hline $50^{\circ}-75^{\circ}$ & $32-2.2 \mathrm{hPa}$ & -22 to $12 \%$ & $23-53 \%$ & 36 & April + May 03, July 03 \\
$75^{\circ}-89^{\circ}$ & $31-2.6 \mathrm{hPa}$ & -21 to $-4 \%$ & $10-32 \%$ & 50 & June 03, July 02/03 \\
$89^{\circ}-91^{\circ}$ & $28-2.3 \mathrm{hPa}$ & -4 to $22 \%$ & $15-30 \%$ & 23 & Feb 04, July 02/03, Dec 02/03 \\
$91^{\circ}-101^{\circ}$ & $30-2.6 \mathrm{hPa}$ & -30 to $-9 \%$ & $19-33 \%$ & 140 & April 03, July 02/03, Sep 03, Dec 02 \\
$101^{\circ}-111^{\circ}$ & $31-2.6 \mathrm{hPa}$ & -37 to $-5 \%$ & $6-24 \%$ & 28 & Jan 03/04, April 03, July 02/03 \\
All & $31-2.5 \mathrm{hPa}$ & -20 to $-5 \%$ & $20-35 \%$ & 277 & \\
\hline
\end{tabular}

Table 5. Statistics of the comparison (MIPAS-SAGE II)/SAGE II NO 2 profiles for different latitudinal regions (zone). Statistical results are given for different pressure altitudes (press. alt.) and only matches within the same air mass are included; mean relative difference (MRD), standard deviation (SD), number of collocations within the SZA range (N) are shown, too.

\begin{tabular}{llllll}
\hline Zone & Press. alt. & MRD & SD & N & Month of year \\
\hline $63^{\circ} \mathrm{S}-80^{\circ} \mathrm{S}$ & $27-2.3 \mathrm{hPa}$ & 0 to $38 \%$ & $17-29 \%$ & 28 & Dec 02/03, Feb 04 \\
$28^{\circ} \mathrm{S}-55^{\circ} \mathrm{S}$ & $30-2.2 \mathrm{hPa}$ & -30 to $7 \%$ & $23-51 \%$ & 63 & Jan 03/04, April-May 03, July 03 \\
$45^{\circ} \mathrm{N}-60^{\circ} \mathrm{N}$ & $32-2.7 \mathrm{hPa}$ & -40 to $-18 \%$ & $10-20 \%$ & 28 & Jan 03, April 03, July 02/03 \\
$60^{\circ} \mathrm{N}-76^{\circ} \mathrm{N}$ & $32-2.7 \mathrm{hPa}$ & -32 to $-11 \%$ & $11-25 \%$ & 158 & April+June 03, July 02/03, Sep 03 \\
\hline
\end{tabular}

\subsubsection{SAGE II comparison}

The Stratospheric Aerosol and Gas Experiment II (SAGE II) on the Earth Radiation Budget Satellite (ERBS) has been launched into its non-sun synchronous orbit in October 1984. SAGE-II is a seven-channel solar occultation instrument collecting aerosol and trace gas data during each sunrise and sunset. It was powered off in August 2005. In this study the $\mathrm{NO}_{2}$ data version 6.2 is used for the intercomparison to MIPAS. The precision and accuracy of $\mathrm{NO}_{2}$ data has been assessed by Cunnold et al. (1991). This former version 5.96 shows an agreement within $10 \%$ to balloon profiles and ATMOS measurements in the altitude range between 23 and $37 \mathrm{~km}$. The photochemical correction has been applied in the same way as for the HALOE-MIPAS comparison. Averaging kernel smoothing of the $\mathrm{NO}_{2}$ profiles could be neglected due to similar vertical resolutions of SAGE II and MIPAS. Differences between both sensors are displayed in Tables 4 and 5. Latitudinal differences of both sensors are shown in Fig. 12. In southern hemisphere mid-latitudes the agreement between MIPAS and SAGE II is quite good. Except the highest (near $1 \mathrm{hPa}$ ) and lowest (below $20 \mathrm{hPa}$ ) altitude levels, where a significant negative bias is visible, differences are within the combined errors. In the northern hemisphere, a significant negative bias is obvious especially for the mid-latitude case where mean relative deviations of more than $20 \%$ are found for most altitudes. It is known that SAGE II $\mathrm{NO}_{2}$ has a positive bias compared to HALOE $\mathrm{NO}_{2}$
(L. Thomason, personal communication, 2004). Bearing this fact in mind this would reduce the mentioned negative bias between MIPAS and SAGE II. However, in the Antarctic, a positive bias of up to $38 \%$ near $30 \mathrm{hPa}$ is visible. In contrast to HALOE, no corrections of variations of the solar zenith angle along the line of sight of SAGE II were performed. This may introduce some inaccuracies in the SAGE II NO 2 data. Payan et al. (1999) estimated such VMR errors to less than $6 \%$. Anyhow, this helps to at least partly explain the comparatively large discrepancies between MIPAS and SAGE II.

\subsubsection{POAM III comparison}

The Polar Ozone and Aerosol Measurement III (POAM III) instrument was carried by the SPOT-4 spacecraft and was launched in March 1998. The instrument failed in December 2005. The solar occultation was performed in nine spectral channels in the visible and near-IR spectral region. The new $\mathrm{NO}_{2}$ data version 4 has been used for the intercomparison with MIPAS. The precision and accuracy of POAM III version $3 \mathrm{NO}_{2}$ data is given by Lumpe et al. (2002). This data has been validated by Randall et al. (2002) showing an agreement to HALOE from 20 to $33 \mathrm{~km}$ within $6 \%$ and from 33 to $40 \mathrm{~km}$ between 6 and $12 \%$. The new POAM III version 4 data is described in a technical note ("Overview of the validation of POAM III version 4 retrievals") available from the public web-site http://wvms.nrl.navy.mil/POAM/poam.html. Differences compared to HALOE (version 19) are within $10 \%$ 

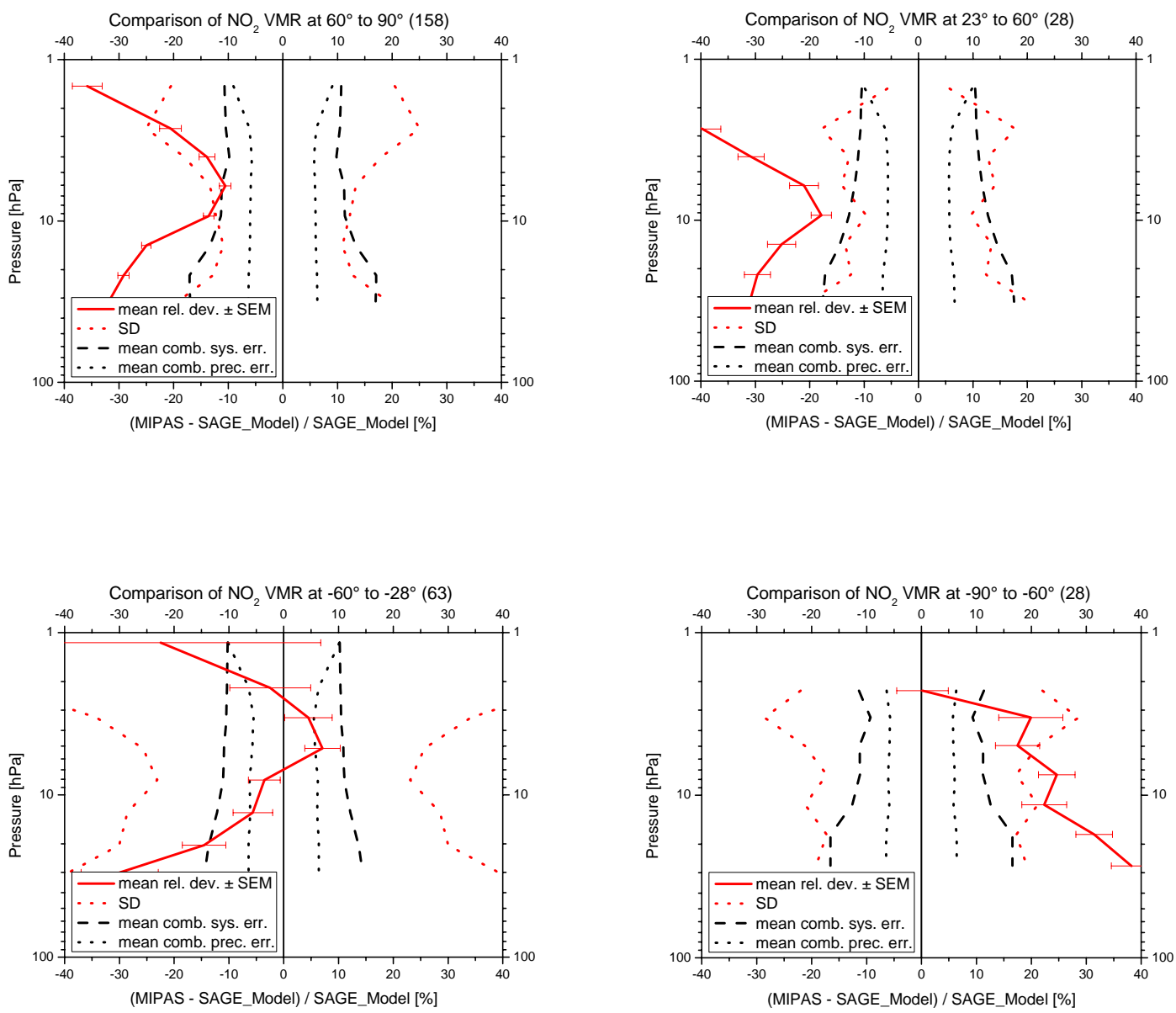

Fig. 12. Mean relative differences (including the standard error of the mean, SEM) between MIPAS and SAGE II for different latitude regions in the northern hemisphere (top) and the southern hemisphere (bottom). Standard deviation (SD) and mean combined precision and systematic errors are plotted, too.

Table 6. Statistics of the comparison (MIPAS-POAM III)/POAM III NO 2 profiles for different seasons (time) in both hemispheres. Statistical results are given for different pressure altitudes (press. alt.) and only matches within the same air mass are included; mean relative difference (MRD), standard deviation (SD), number of collocations (N) within the solar zenith angle (SZA) and latitude range are shown, too.

\begin{tabular}{lllllll}
\hline Time & Press. alt. & MRD & SD & N & SZA & Latitude \\
\hline Northern hemisphere (March 2003-Sep 2003) & & & \\
Spring & $36-4.3 \mathrm{hPa}$ & -46 to $-10 \%$ & $9-14 \%$ & 36 & $97^{\circ}-106^{\circ}$ & $54^{\circ} \mathrm{N}-63^{\circ} \mathrm{N}$ \\
Summer & $34-3.8 \mathrm{hPa}$ & -27 to $0 \%$ & $8-17 \%$ & 61 & $98^{\circ}-107^{\circ}$ & $56^{\circ} \mathrm{N}-71^{\circ} \mathrm{N}$ \\
Winter & $14-3.9 \mathrm{hPa}$ & 2 to $15 \%$ & $5-31 \%$ & 10 & $106^{\circ}-109^{\circ}$ & $65.7^{\circ} \mathrm{N}-67^{\circ} \mathrm{N}$ \\
All & $22-4.0 \mathrm{hPa}$ & -9 to $8 \%$ & $11-18 \%$ & 107 & & \\
Southern hemisphere (Nov 2002-Nov 2003) & & & \\
Spring & $22-3.1 \mathrm{hPa}$ & -7 to $28 \%$ & $10-48 \%$ & 125 & $89.6^{\circ}-93.5^{\circ}$ & $68^{\circ} \mathrm{S}-82^{\circ} \mathrm{S}$ \\
Summer & $31-3.6 \mathrm{hPa}$ & -7 to $16 \%$ & $11-17 \%$ & 56 & $91.7^{\circ}-96^{\circ}$ & $67^{\circ} \mathrm{S}-78^{\circ} \mathrm{S}$ \\
Fall & $4-2.3 \mathrm{hPa}$ & -20 to $-14 \%$ & $40-53 \%$ & 43 & $89.9^{\circ}-93^{\circ}$ & $63^{\circ} \mathrm{S}-83^{\circ} \mathrm{S}$ \\
Winter & No comparison due to large mean standard deviation & \\
All & $27-2.8 \mathrm{hPa}$ & -16 to 32\% & $20-60 \%$ & 224 & (without winter measurements) \\
\hline \multicolumn{7}{c}{}
\end{tabular}



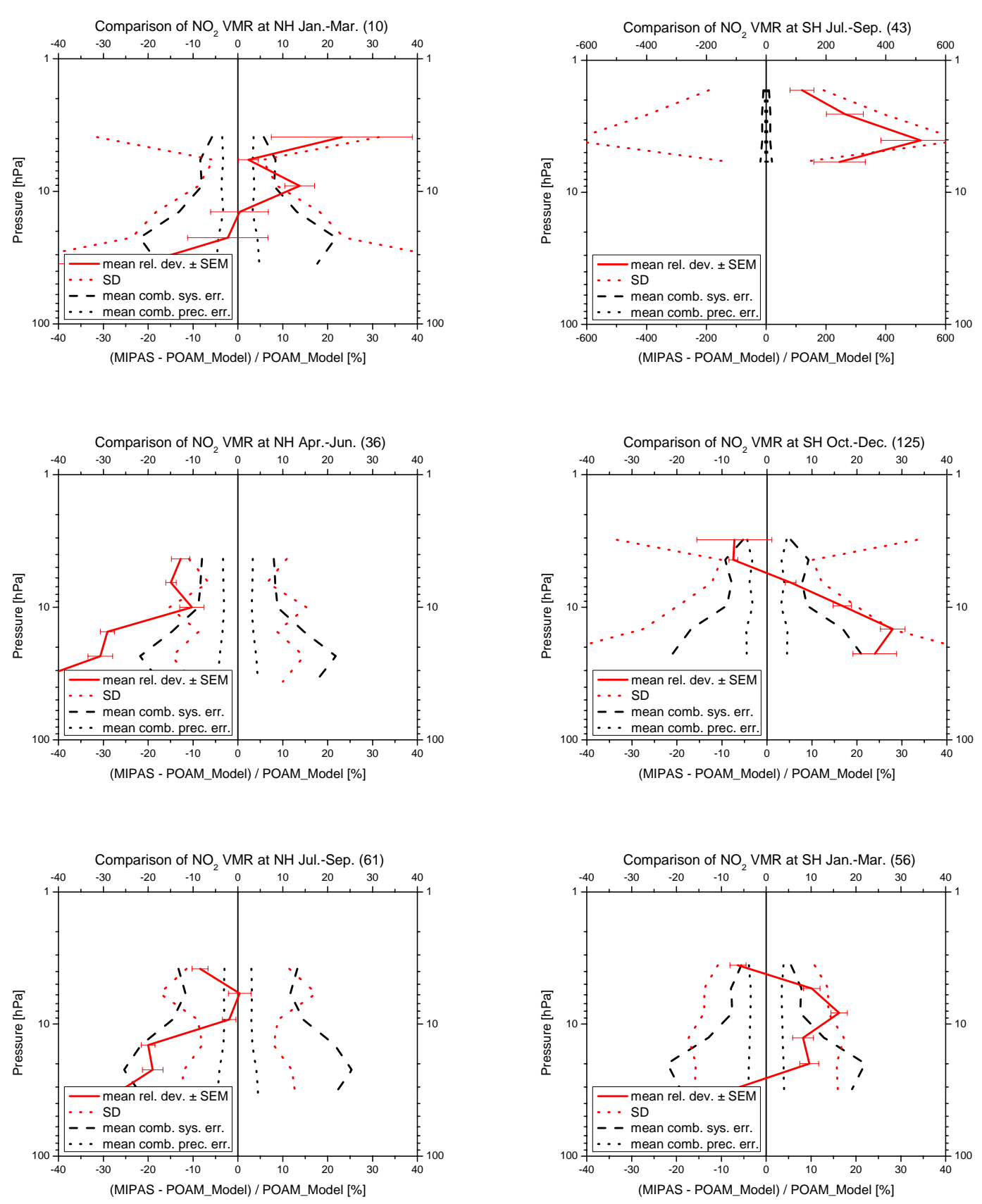

Fig. 13. Mean relative differences (including the standard error of the mean, SEM) between MIPAS and POAM III for different seasons: winter (top), spring (middle), summer (bottom) in the northern (left) and southern (right) hemisphere. Standard deviation (SD) and mean combined precision and systematic errors are plotted, too (please note different scale for the graph top right).

from $25-35 \mathrm{~km}$, but approach $20 \%$ or higher (POAM higher than HALOE) near $20 \mathrm{~km}$ and $40 \mathrm{~km}$. POAM III sunrise or sunset data and SAGE II (version 6.2) sunset data is within $\pm 10 \%$ from $25-35 \mathrm{~km}$. Comparisons with SAGE II sunrise data, however, suggest a SAGE II sunrise negative bias of more than $15 \%$. The photochemical correction was applied like in the previous satellite comparisons. A smoothing with averaging kernels was not necessary due to similar vertical resolutions of POAM III and MIPAS. Differences between both sensors in dependence of season are given in Table 6 and Fig. 13. In the northern hemisphere (NH) winter (January to March) measurements of both sensors agree within about $15 \%$. In the $\mathrm{NH}$ spring (April to June) a negative bias in MIPAS $\mathrm{NO}_{2}$ is visible exceeding $15 \%$ at altitudes below 
about $10 \mathrm{hPa}$. A negative bias appears also in the $\mathrm{NH}$ summer (July to September) observations, especially below $10 \mathrm{hPa}$, but due to the quite large combined systematic errors this bias is not significant. The comparison in SH summer (January to March) exhibits an agreement of both sensors within $15 \%$. Except the altitude region below about $10 \mathrm{hPa}$ this holds also for the SH spring comparison (October to December). In the SH fall (April to June, see Table 6) below $4 \mathrm{hPa}$ and winter (July to September, see Fig. 13) very large deviations between MIPAS and POAM occur, which might be connected to observations near and across the vortex edge and/or connected limitations of the correction with the photochemical model. One reason could be effects of strong horizontal gradients in temperature and $\mathrm{NO}_{2}$ along the line of sight which are not included in the $\mathrm{NO}_{2}$ data retrievals. This holds for the SH winter where no comparison was possible due to large standard deviations. It should be mentioned that POAM SH measurements (and therefore the MIPAS-POAM SH collocations) have been performed at higher latitudes $\left(63^{\circ} \mathrm{S}\right.$ to $\left.83^{\circ} \mathrm{S}\right)$ as compared to the $\mathrm{NH}$ latitudes $\left(54^{\circ} \mathrm{N}\right.$ to $\left.71^{\circ} \mathrm{N}\right)$. This explains the higher possibility of polar vortex coverage. Like SAGE II, no corrections of variations of the solar zenith angle along the line of sight of POAM III were performed what may introduce inaccuracies in the POAM III vertical $\mathrm{NO}_{2}$ profiles. On the other hand, it should be emphasized that under extreme winter conditions standard $\mathrm{NO}_{2}$ microwindows used by the MIPAS retrieval processor do not contain significant information in the lower stratosphere such that the $\mathrm{NO}_{2}$ data are not very reliable in this case (see also Sect. 3.2.5).

\subsubsection{ACE comparison}

The Atmospheric Chemistry Experiment (ACE), on the SCISAT-1 satellite, was launched into its orbit in August 2003 (Bernath et al., 2005). The primary instrument is a high resolution $\left(0.02 \mathrm{~cm}^{-1}\right)$ Fourier transform spectrometer (ACE-FTS) operating between 750 and $4400 \mathrm{~cm}^{-1}$ in solar occultation. In this work, we only examine results from the FTS, and hereafter refer to the ACE-FTS simply as ACE. Vertical profiles of various atmospheric constituents are retrieved from measured spectra with a vertical resolution of $3-$ $4 \mathrm{~km}$ with a nearly global coverage from about $85^{\circ} \mathrm{N}$ to $85^{\circ} \mathrm{S}$ with a majority of observations in the Arctic and Antarctic. $\mathrm{NO}_{2}$ profile comparisons (data version 1.0) to HALOE version $19 \mathrm{NO}_{2}$ have shown that both sensors agree within $10 \%$ between 22 and $35 \mathrm{~km}$ altitude with lower values of ACE compared to HALOE (McHugh et al., 2005). For this study, only arctic daytime sunset profiles (data version 2.2) around $75^{\circ} \mathrm{N}$ are compared to MIPAS daytime observations. A photochemical correction has been applied to the data with the help of calculations performed by the three dimensional CTM KASIMA according to the method described in Sect. 3.1. The limited horizontal resolution of the model may introduce systematic inaccuracies in the photochemical correction when transferring the sunset ACE data to the time and

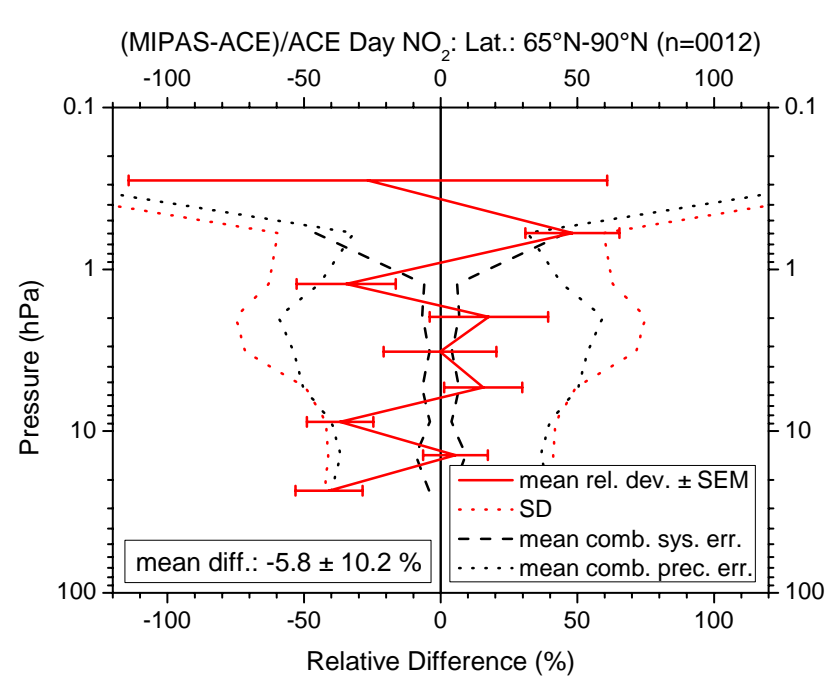

Fig. 14. Mean relative difference (including the standard error of the mean, SEM) of MIPAS and ACE $\mathrm{NO}_{2}$ profiles (12 collocations) between $65^{\circ}$ and $90^{\circ} \mathrm{N}$ latitude in February and March 2004 (red solid line). Random (black dotted line) and systematic (black dashed line) parts of the combined errors are shown together with the standard deviation (red dotted line). Some significant systematic differences appear mainly below about $6 \mathrm{hPa}$ pressure altitude (about $32 \mathrm{~km}$ ).

location of MIPAS day measurements. To avoid such effects, the collocation criterion was tightened in terms of time and set to $1 \mathrm{~h}$.

The mean difference of all collocations (between 4 February and 26 March 2004) is shown in Fig. 14. The overall agreement of both sensors is very good. A tendency to a small negative bias is visible for pressure altitudes below $6 \mathrm{hPa}$ (about $32 \mathrm{~km}$ ) and extends to about $40 \%$ at the lowest altitude level. However, the overall negative mean bias is only $5.8 \%$ and remains mostly within the combined systematic error, which is underestimated since no systematic error data is available for the ACE observations.

\subsubsection{Retrieval processor comparison}

It has been shown that atmospheric $\mathrm{NO}_{2} \nu_{3}$ IR emissions might depart from local thermodynamic equilibrium (LTE) in the mesosphere and upper stratosphere (see, e.g., LópezPuertas and Taylor, 2001). An innovative non-LTE retrieval scheme (Funke et al., 2001) has been included in the scientific MIPAS data processor (von Clarmann et al., 2003) developed at the Institut für Meteorologie und Klimaforschung (IMK) and the Instituto de Astrofísica de Andalucía (IAA). In contrast to the ESA operational processor, the IMK/IAA retrieval code allows accurate inference of $\mathrm{NO}$ and $\mathrm{NO}_{2}$ volume mixing ratios under consideration of all important nonLTE processes. Main results of this processor comparison are depicted in Fig. 15. These comparisons have been performed for undisturbed conditions (24 September 2002) and 

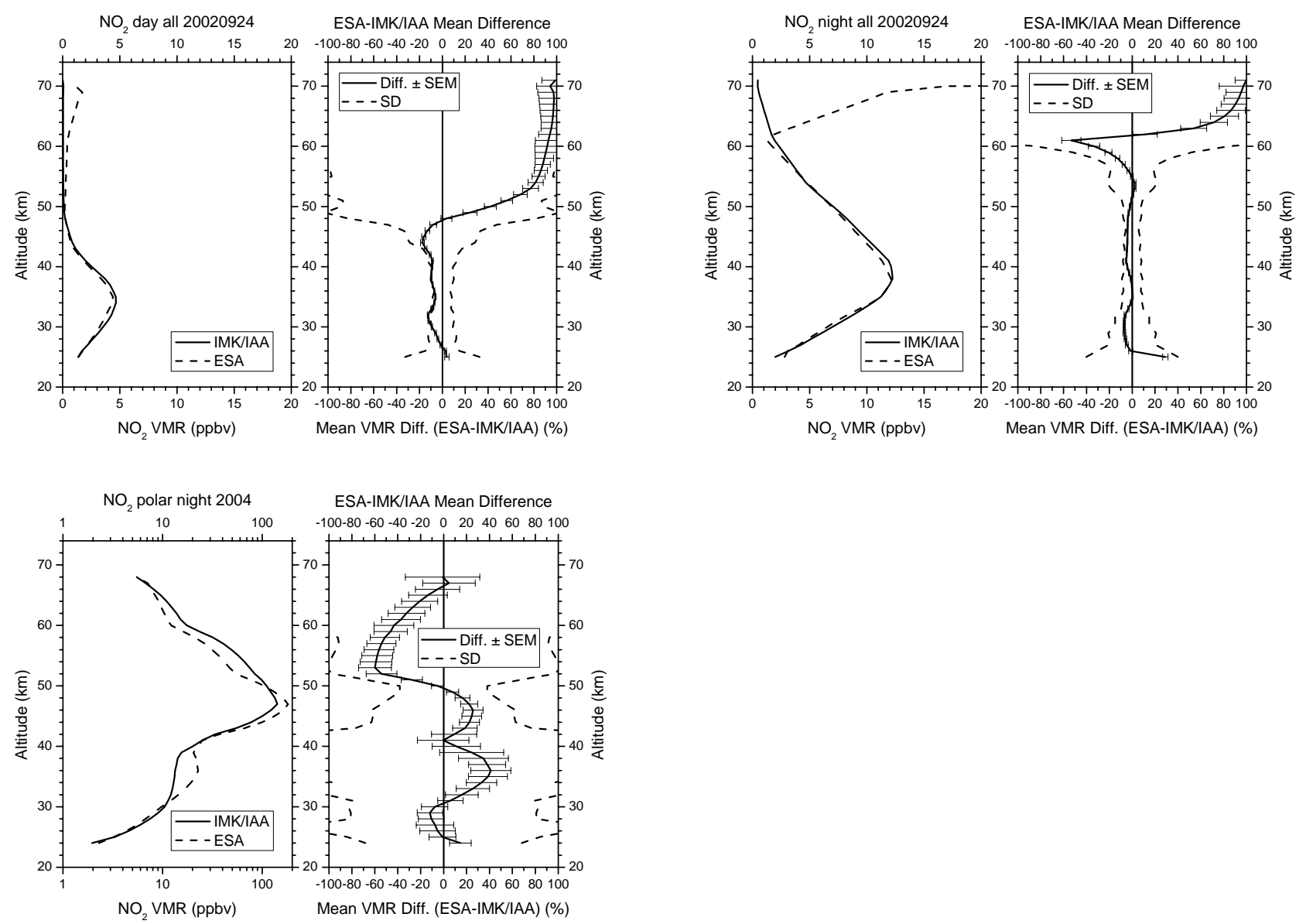

Fig. 15. Comparison of MIPAS $\mathrm{NO}_{2}$ profiles and mean deviations (including the standard error of the mean, SEM, and the standard deviation, SD) retrieved by the IMK/IAA scientific and ESA operational processors from sequences measured on 24 September 2002 during day (top left) and night (top right). Mean polar night profiles and deviations within the period from 17 February to 25 March 2004 are also shown (bottom, please note different scale in left graph). The comparison is performed on a pressure grid although altitudes are shown.

perturbed conditions (nighttime only, NH winter 2003/2004) with a strong subsidence of mesospheric $\mathrm{NO}_{\mathrm{x}}$. Large differences appear especially at higher altitudes above about 50 to $55 \mathrm{~km}$ for the September comparison. ESA results at these high altitudes show extremely high variability. IMK/IAA retrievals have shown that residuals could be significantly reduced by readjusting the collisional rate for $\mathrm{N}_{2}$ to a value 20 times higher than the nominal one. The non-LTE effect in $\mathrm{NO}_{2} 6.2 \mu \mathrm{m}$ emissions is thus less important than previously estimated (i.e. up to 30\%, Funke et al., 2005a) and generally amounts to only $3 \%$, although more than $20 \%$ can be reached under extreme polar winter conditions above $60 \mathrm{~km}$. Non-LTE, however, cannot account alone for the discrepancy at these altitudes.

In the stratosphere (September 2002 case) the ESA retrievals yield up to $10 \%$ lower $\mathrm{NO}_{2}$ volume mixing ratios during day and mostly less than 5\% during nighttime compared to the IMK/IAA retrievals. The instrumental line shape
(ILS) models of IMK/IAA and ESA used for the retrievals are slightly different. Sensitivity studies for the September case have shown that this could partly explain the VMR differences between ESA and IMK/IAA retrievals. Differences in temperature profiles used for the $\mathrm{NO}_{2}$ retrievals have been checked for 24 September 2002. In general, ESA retrieved temperatures are higher than those inferred by IMK/IAA by up to $5 \mathrm{~K}$ at $70 \mathrm{~km}$ and $1-2 \mathrm{~K}$ between 35 and $50 \mathrm{~km}$ altitude. Estimating the Planck function effect for $\mathrm{NO}_{2}$ emissions at $1600 \mathrm{~cm}^{-1}$, a $1.5 \mathrm{~K}$ overestimation by ESA would result in roughly $6 \%$ underestimation of $\mathrm{NO}_{2}$ volume mixing ratios. This helps to explain differences between ESA and IMK/IAA retrievals below $50 \mathrm{~km}$ altitude.

The comparison of IMK/IAA and ESA retrievals during perturbed conditions (winter 2003/04, see Fig. 15, bottom) shows qualitatively good agreement (note, that $\mathrm{NO}_{2}$ VMRs at these conditions vary over several orders of magnitude), although ESA values are 10-40\% higher between 30 and 
$40 \mathrm{~km}$ and $20-60 \%$ lower at 50-65 km. Differences above $50 \mathrm{~km}$ might be explained at least partly by non-LTE (under polar winter conditions); below they are probably related to horizontal $\mathrm{NO}_{2}$ gradients, which are explicitly treated in the IMK/IAA retrieval, and differences in the retrieved temperature profiles. It should be noted that whenever $\mathrm{NO}_{2}$ values are very high in the upper stratosphere and lower mesosphere, which was the case in the Antarctic polar region in winter 2003 (Funke et al., 2005b) and in the Arctic winter 2003/04, $\mathrm{NO}_{2}$ values retrieved by the operational processor at $30 \mathrm{~km}$ and below suffer from very large errors. The reason seems to be that under these extreme conditions standard $\mathrm{NO}_{2}$ microwindows used by the ESA processor do not contain significant information in the lower stratosphere. This fact can also help to explain why large deviations prevented a reasonable comparison between MIPAS and POAM III in the Antarctic winter 2003 (cp. Sect. 3.2.3).

\subsection{Intercomparison of NDACC ground-based observa-} tions

Nitrogen dioxide is one of the key species monitored from pole to pole by the ground-based Network for the Detection of Atmospheric Composition Change (NDACC), a main contributor to WMO's Global Atmosphere Watch program and formerly known as the Network for the Detection of Stratospheric Change (NDSC). In the framework of this worldwide network of high-quality remote-sounding stations, two different measurement techniques provide complementary observations of the vertical column amount and profile of $\mathrm{NO}_{2}$ and its diurnal variation along the day. Sunrise and sunset columns are retrieved from zenith-scattered sunlight absorption measurements in the $400-500 \mathrm{~nm}$ range performed year-round by more than 30 Differential Optical Absorption (DOAS) UV-visible spectrometers (Roscoe et al., 1999; Vandaele et al., 2005, and references therein). Daytime $\mathrm{NO}_{2}$ column is retrieved at various solar zenith angles from solar radiation absorption measurements by the $\mathrm{NO}_{2}$ multiplet at $2914.65 \mathrm{~cm}^{-1}$ performed, weather permitting, by about 10 Fourier Transform infrared (FTIR) spectrometers (Notholt and Schrems, 1994; De Mazière et al., 1998). Both measurement techniques are sensitive mainly to the stratospheric part of the vertical column. In addition to those column retrievals, height-resolved information on $\mathrm{NO}_{2}$ is also derived at a few NDACC/DOAS stations taking into account the significant variation of the mean scattering height of zenith-sky observations during twilight (McKenzie et al., 1991; Hendrick et al., 2004). The independent validation of atmospheric chemistry satellite missions is a main objective of the NDACC (Lambert et al., 1999). Although measuring stratospheric $\mathrm{NO}_{2}$ at poor vertical resolution, its ability to provide high-quality, continuous time-series at a variety of sites from pole to pole has been helpful in validating seasonal signals and meridian structures reported by $\mathrm{NO}_{2}$ satellite sensors like HALOE (Gordley et al., 1996), GOME (Lambert et al., 2002), POAM
III (Randall et al., 2002) and SCIAMACHY (Piters et al., 2006). In this section we will study how partial stratospheric columns derived from MIPAS measurements are consistent with correlative observations reported by the various components of the NDACC.

The confrontation of MIPAS and NDACC data has to address two main issues: the diurnal variation of $\mathrm{NO}_{2}$ which can generate dramatic differences between data recorded at different hours of the day, and the fact that MIPAS accuracy degrades rapidly at altitudes below $24 \mathrm{~km}$. FTIR observations can offer the best time coincidence with MIPAS data acquired in the mid-morning part of the orbit, without the use of a photochemical model to allow for time differences of less than $1 \mathrm{~h}$. We will concentrate here on the instrument at the Institutet foer Rymdfysik (IRF) in Kiruna (Arctic Sweden, $67.8^{\circ} \mathrm{N}, 20.4^{\circ} \mathrm{E}$ ). It is operated by IMK Karlsruhe, IRF Kiruna, and University of Nagoya. This instrument records atmospheric absorptions of the infrared solar spectrum with a high spectral resolution of approximately $0.003 \mathrm{~cm}^{-1}$. Experimental details have been published elsewhere (e.g. Blumenstock et al., 1997). Measured spectra are evaluated using the retrieval code PROFFIT (Hase et al., 2004), one of the reference codes accepted by the NDACC, and the forward model KOPRA (Stiller et al., 2002). Spectroscopic parameters are taken from the HITRAN database (Rothman et al., 2005). The precision of individual $\mathrm{NO}_{2}$ measurements performed by FTIR spectrometry is less than $10 \%$ (Sussmann et al., 2005). The accuracy is estimated to be about $10 \%$. The spectroscopic characteristics of the $\mathrm{NO}_{2}$ multiplet (weak lines, interfering with strong methane absorptions) make it impossible to separate the contribution of the tropospheric $\mathrm{NO}_{2}$ column to the measured absorption. In fact, the absorption of the tropospheric $\mathrm{NO}_{2}$ column is covered by broad band absorption of methane and therefore the retrieved $\mathrm{NO}_{2}$ column amount is representative mainly for the stratospheric column.

Results of the FTIR-based comparison in Kiruna are displayed in Fig. 16 for the period February until September 2003. No significant deviations are visible between MIPAS columns, calculated directly from the profile VMRs or calculated after smoothing to the altitude resolution of the groundbased FTIR. The seasonal variation of the $\mathrm{NO}_{2}$ columns is captured similarly by both instruments. Differences between FTIR and MIPAS partial columns are very small in summer with less than $10 \%$ and without a bias. However, in autumn (September) and winter, deviations are larger and reach up to $45 \%$ on 24 February 2003 with a general positive bias in the MIPAS data. The PV difference at $475 \mathrm{~K}$ is within $15 \%$ for these collocations.

The problem of altitude limitations of MIPAS can be minimized when comparing with height-resolved data retrieved from ground-based UV-visible spectra measured before and during twilight. Here, we will concentrate on the instrument operated by BIRA-IASB in Harestua (Southern Norway, $60.2^{\circ} \mathrm{N}, 10.8^{\circ} \mathrm{E}$ ). Details on the instrument and the 


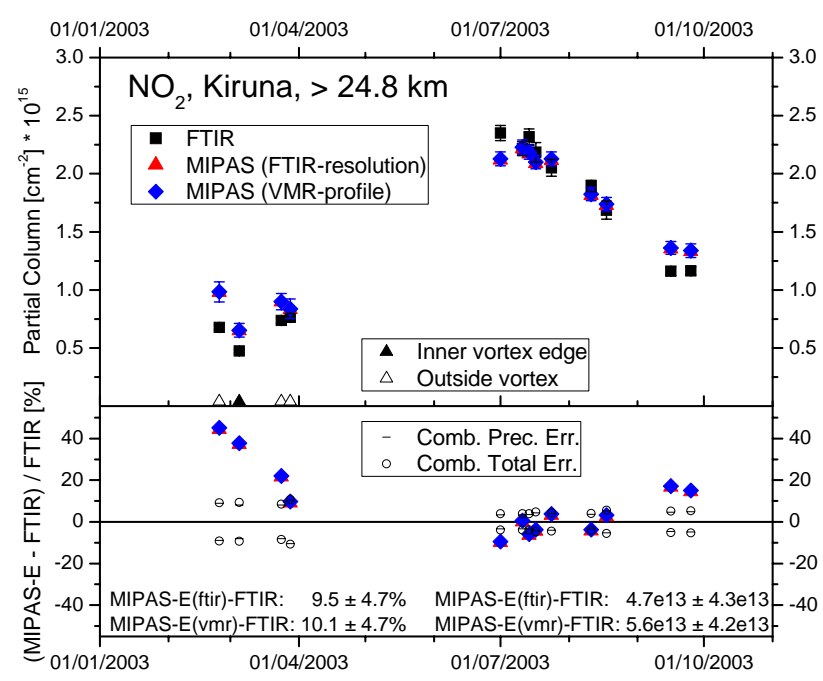

Fig. 16. Comparison of $\mathrm{NO}_{2}$ partial column amounts above $24.8 \mathrm{~km}$ to integrated MIPAS columns for the year 2003, measured at Kiruna $\left(68^{\circ} \mathrm{N}\right.$, Sweden). MIPAS partial columns have been calculated from both the smoothed profile (MIPAS(FTIR-resolution)) and from the unsmoothed profile (MIPAS(VMR-profile)).

DOAS analysis settings can be found in Roscoe et al., 1999 and Vandaele et al., 2005, respectively. The retrieval of a $\mathrm{NO}_{2}$ profile is based on the dependence of the mean scattering height of zenith-sky spectra on the solar zenith angle (Hendrick et al., 2004). A stacked photochemical box model is included in the retrieval algorithm in order to reproduce the effect of the rapid variation of the $\mathrm{NO}_{2}$ concentration along the optical path, particularly significant at twilight. A total error is calculated taking into account measurement, smoothing, and forward model errors. The resulting vertical resolution of the retrieved $\mathrm{NO}_{2}$ profile is about $10 \mathrm{~km}$. To minimize errors due to differences in vertical smoothing, MIPAS $\mathrm{NO}_{2}$ profiles are smoothed using the averaging kernels and the a priori profile associated with the ground-based retrievals. From the comparison of the averaging kernels of both instruments it can be deduced that the altitude region between 26.5 and $36.5 \mathrm{~km}$ is most relevant for the comparison of partial columns. MIPAS tangent points are selected within a radius of $750 \mathrm{~km}$ around the station for the same days. Since a photochemical box model is included in the forward model, ground-based UV-visible profiles are retrieved at the SZA corresponding to the MIPAS observation, minimizing errors due to diurnal cycle effects. Results of this comparison are shown in Fig. 17 including data from July 2002 to October 2003. A mean negative bias in the MIPAS partial columns of $15 \%$ for daytime and $8 \%$ for nighttime coincident events is visible. For nighttime events, the bias clearly changes over the year with a negative bias in spring-summer and a positive bias in late summer-early fall. The possible impact on this behaviour of the uncertainty on the SZA correction has been investigated through sensitivity tests performed us- ing the BIRA-IASB photochemical box model. These tests have shown that the uncertainty on the SZA correction can only partly explain the seasonality in the nighttime bias. Further investigations are therefore required to find the exact ori$\operatorname{gin}(\mathrm{s})$ of this bias seasonality. However, it should be noted that for most coincidences, differences between MIPAS and ground-based partial columns are not significant since they are well inside the combined systematic errors.

To investigate possible meridian errors in MIPAS $\mathrm{NO}_{2}$ data, and to extend the investigation of seasonal errors at a larger amount of sites, we have also conducted comparisons with the entire DOAS/UV-visible network of the NDACC, which samples the latitude range from $79^{\circ} \mathrm{N}$ to $78^{\circ} \mathrm{S}$ with about 35 stations archiving data regularly to the NDACC central archive or to the ENVISAT Cal/Val data centre. During intercomparison/certification campaigns, the agreement between collocated instruments generally falls within the $3 \%$ to $8 \%$ range (Vandaele et al., 2005). Long-term comparisons of nearly co-located slant column measurements at middle latitudes conclude to a similar mean agreement of 3\% in summer and 9\% in winter (Koike et al., 1999). The precision on the spectral fitting is much better than $1 \%$. Although all NDACC/UV-visible stations provide a comparable level of precision, the final accuracy of a ground-based $\mathrm{NO}_{2}$ column data record is determined by the choice of the $\mathrm{NO}_{2}$ crosssection temperature used for the spectral fitting of the spectra (Vandaele et al., 1998): on-site real-time retrieval algorithms using cross-sections at room temperature generate a systematic offset of 10-20\% compared to state-of-the-art algorithms using cross-sections at stratospheric temperature.

To enable quantitative comparisons with MIPAS $\mathrm{NO}_{2}$ data, we minimize the problems of MIPAS altitude limitations and of the diurnal cycle as follows. First, only 23 DOAS stations found in a sufficiently clean tropospheric environment - to provide a good estimate of the $\mathrm{NO}_{2}$ stratospheric column - are used for testing MIPAS stratospheric data. Second, MIPAS profiles are completed down to the tropopause - determined from ECMWF meteorological analyses - with $\mathrm{NO}_{2}$ profiles generated by the $4 \mathrm{D}$-variational data assimilation system BASCOE (Errera and Fonteyn, 2001). This chemical-transport model of the stratosphere is driven by meteorological analyses of the ECMWF (winds, pressure and temperature) and constrained with MIPAS profile data of all available species, including $\mathrm{NO}_{2}$. MIPAS profiles are thus completed downwards with a chemically and dynamically consistent extrapolation, rather than the output of an independent model. This so-called "ghost" column added between the lowest available MIPAS altitude and the tropopause contributes to $10 \%$ of the total $\mathrm{NO}_{2}$ day column in the tropics, and up to $40 \%$ in mid-latitude winter, as shown in Fig. 18. MIPAS profile data are selected for comparisons within a radius of less than $300 \mathrm{~km}$ around the station. Third, the aforementioned photochemical model used in the ground-based $\mathrm{NO}_{2}$ profiling (Hendrick et al., 2004) has been used to allow for time differences between the mid-morning MIPAS 
Harestua (Norway, $60^{\circ} \mathrm{N}$ ) - Daytime 26.5-36.5 km, $\mathrm{NO}_{2}$ partial column
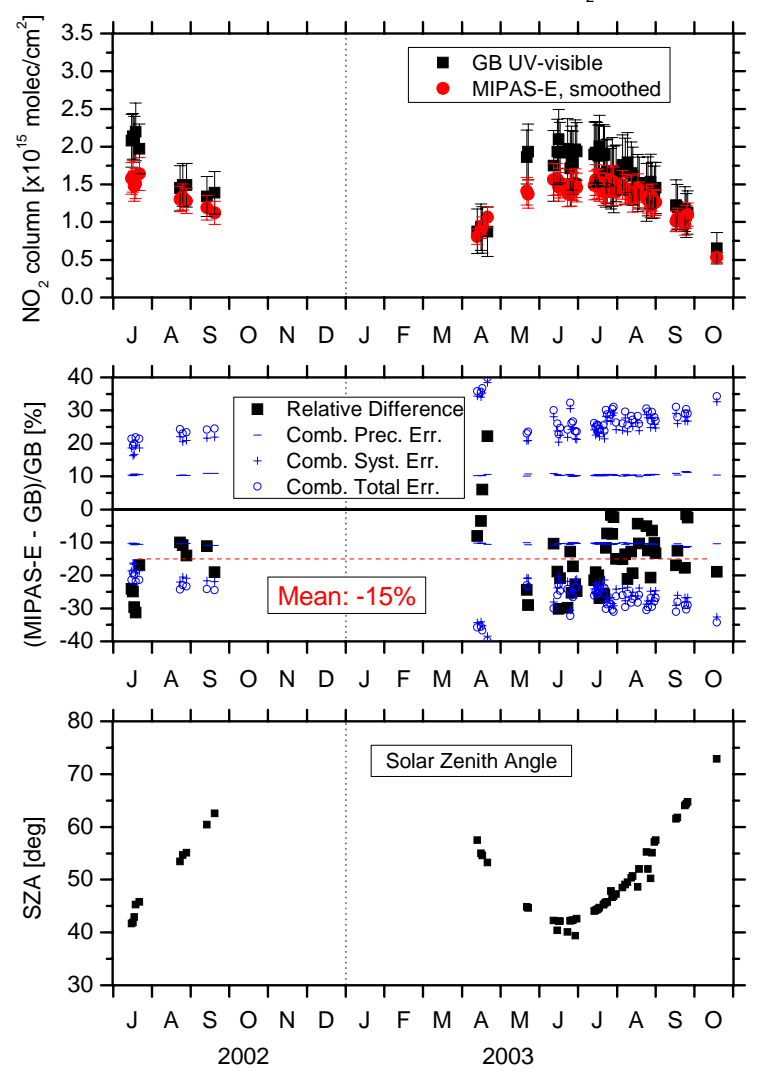

Harestua (Norway, $60^{\circ} \mathrm{N}$ ) - Nighttime $26.5-36.5 \mathrm{~km}, \mathrm{NO}_{2}$ partial colum
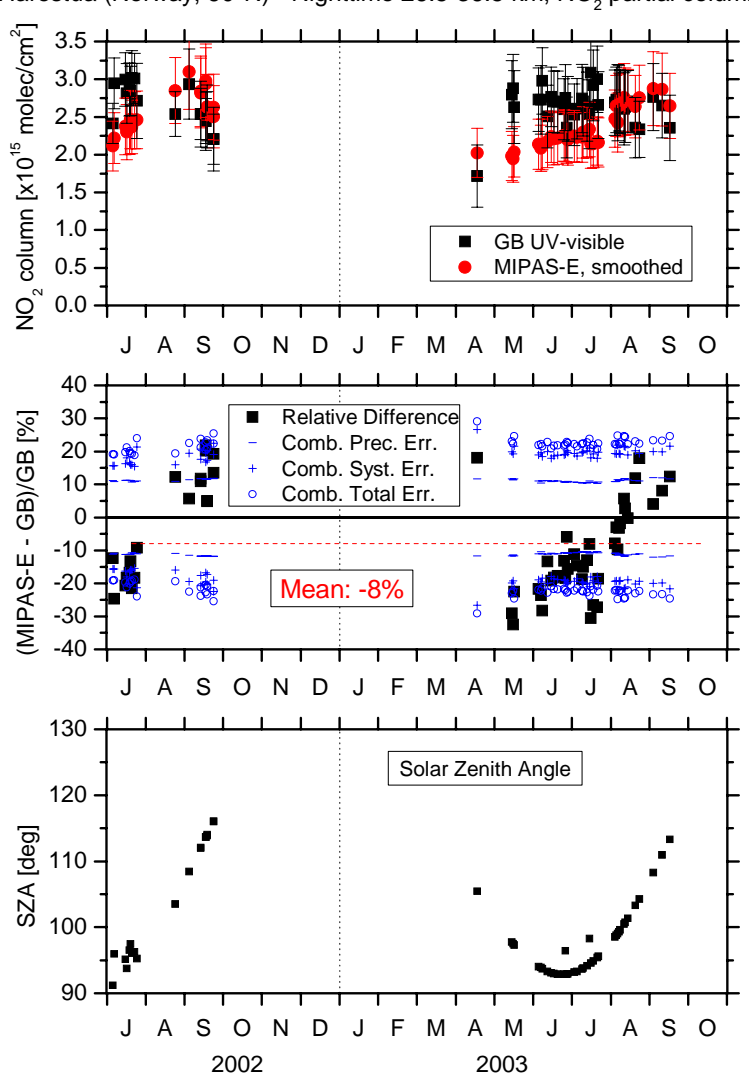

Fig. 17. Comparison of $\mathrm{NO}_{2}$ partial columns (26.5 to $\left.36.5 \mathrm{~km}\right)$ observed at Harestua station $\left(60^{\circ} \mathrm{N}\right.$, Norway) together with differences and combined (precision, systematic, and total) errors as well as solar zenith angles for daytime (left) and nighttime (right) coincident events.

measurement and the twilights. Usually, at low and middle latitudes the sunrise and mid-morning columns are found to agree within a few $10^{14}$ molec $\mathrm{cm}^{-2}$, the difference varying slowly with the season and the latitude. Ground-based DOAS/UV-visible sunrise and MIPAS mid-morning column data can thus be compared on an annual average within this accuracy limit. At higher latitudes, during polar day or under white nights conditions, a photochemical adjustment based on modelling results must be used to deal with the particular U-shape of the diurnal cycle controlled here directly by the photochemical equilibrium of $\mathrm{NO} / \mathrm{NO}_{2}$. Figure 18 details how annual cycles of $\mathrm{NO}_{2}$ are captured by MIPAS at the NDACC stations of the Jungfraujoch (Swiss Alps) and Dumont d'Urville (French Antarctica). In the Alps, the agreement on the annual cycle is within the comparison error budget. In Antarctica, the enhanced natural variability during springtime increases the scatter of the comparison, nevertheless the mean agreement remains within the accuracy limits of the comparison technique. In summertime, a slowly decreasing negative difference is observed, that might be interpreted partly as a residual photochemical difference between the MIPAS and ground-based measurements.
Results of the pole-to-pole comparison are shown in Fig. 19. In general, the 2003 mean agreement between MIPAS and ground-based $\mathrm{NO}_{2}$ column data falls within the accuracy limit of the comparison method, that is, a few $10^{14}$ molec $\mathrm{cm}^{-2}$, which corresponds to better than $10 \%$ in polar summer and up to $30 \%$ and more in polar and middle latitude winter. A distinction is made in Fig. 19 between data retrieved with absorption cross-sections at stratospheric temperatures (black dots), and data retrieved with cross-sections at room temperature (grey squares). If we take into account the positive offset of 15\%-20\% characteristic of the latter data, that is, about $5 \times 10^{14}$ molec $\mathrm{cm}^{-2}$ on an annual average, the agreement with MIPAS at the concerned stations also falls within the accuracy limit of the comparison method.

\section{Summary and conclusions}

The objective of this study is to validate MIPAS operational $\mathrm{NO}_{2}$ profiles by comparison to other independent $\mathrm{NO}_{2}$ observations carried out by different previously validated instruments. In addition, it may also be helpful to better characterize the MIPAS data product by intercomparing it to 

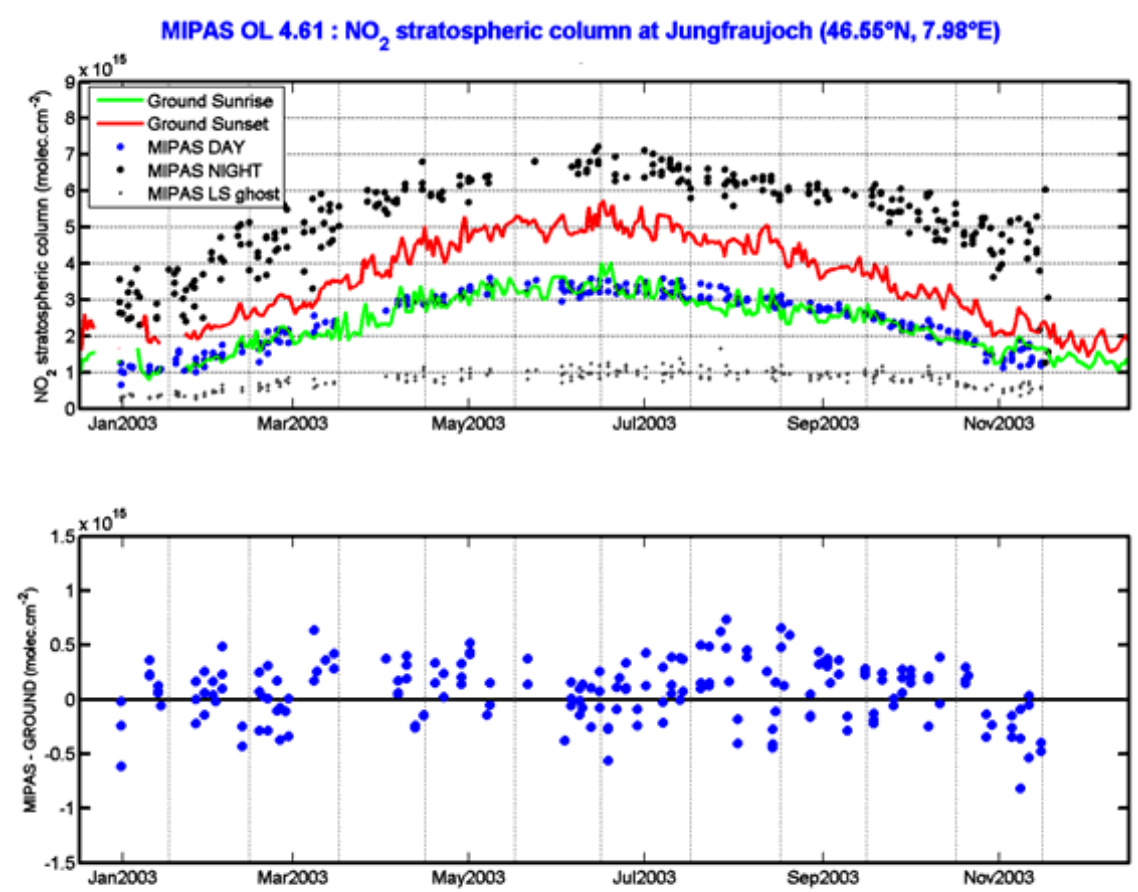

(a)

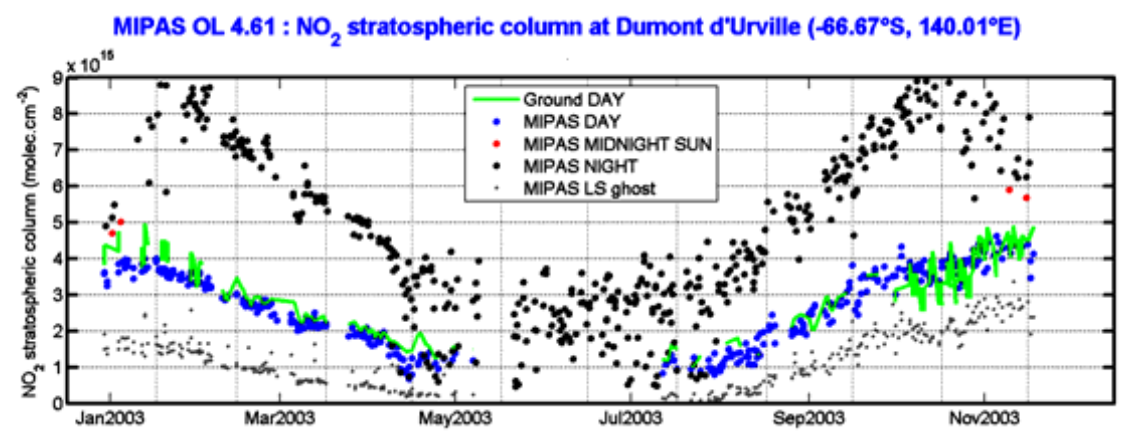

(b)

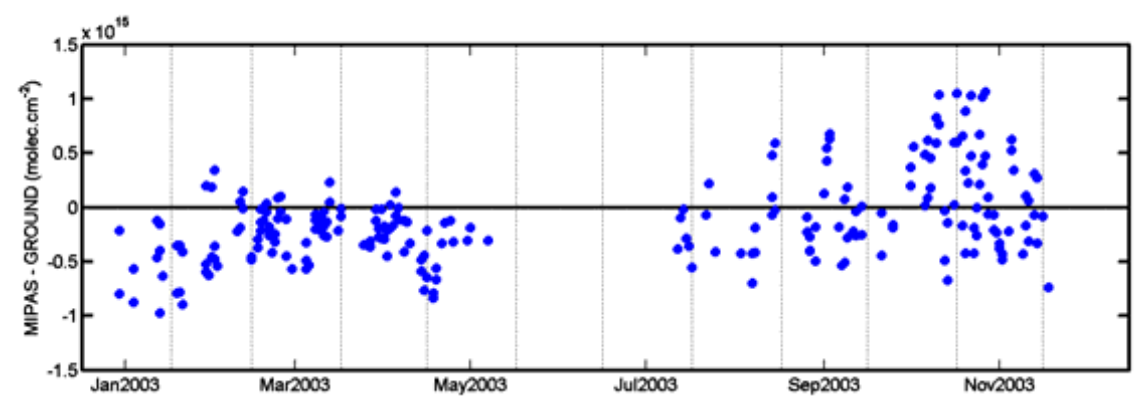

Fig. 18. Seasonal variation in 2003 of the absolute difference between MIPAS version 4.61 and ground-based $\mathrm{DOAS} / \mathrm{UV}-\mathrm{visible} \mathrm{NO} 2$ column data at the NDACC stations Jungfraujoch (Swiss Alps) and Dumont d'Urville (French Antarctica). Ground-based morning (sunrise), afternoon (sunset) and UV-visible column (photochemically corrected with respect to MIPAS day) measurements are shown together with MIPAS day, night, and midnight sun observations and the lower stratospheric "ghost" column (panel a, top, and b, top). Differences are shown between MIPAS (day) and ground-based (sunrise) observations (panel a, bottom) and between MIPAS (day) and ground-based UV-visible column (panel b, bottom). 


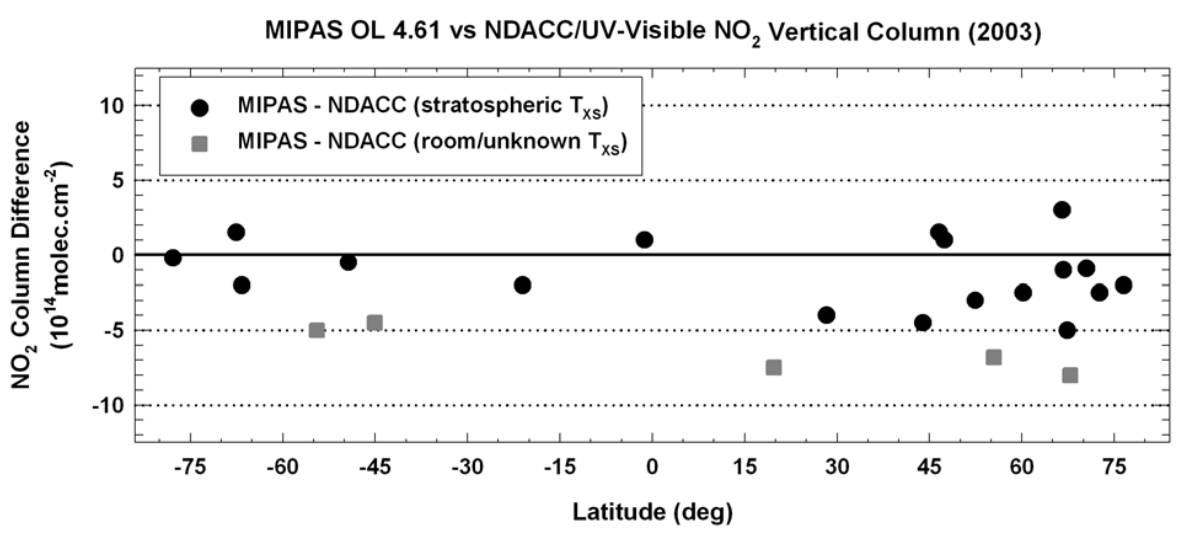

Fig. 19. Yearly average of absolute differences between MIPAS-derived $\mathrm{NO}_{2}$ stratospheric columns and ground-based vertical columns measured at NDACC stations for 2003. The following stations have been used: Arrival Heights $\left(-78^{\circ} \mathrm{S}, 167^{\circ} \mathrm{E}\right.$, UV-visible spectrometer operated by NIWA (National Institute of Water and Atmospheric Research)), Rothera $\left(68^{\circ} \mathrm{S}, 68^{\circ} \mathrm{W}\right.$, NERC/BAS (National Environment Research Council/British Antarctic Survey)), Dumont d'Urville ( $-67^{\circ} \mathrm{S}, 140^{\circ} \mathrm{E}, \mathrm{CNRS}$ (Centre National de la Recherche Scientifique)), Macquarie $\left(-54^{\circ} \mathrm{S}, 159^{\circ} \mathrm{E}\right.$, NIWA), Kerguelen $\left(-49^{\circ} \mathrm{S}, 70^{\circ} \mathrm{E}, \mathrm{CNRS}\right)$, Lauder $\left(-45^{\circ} \mathrm{S}, 170^{\circ} \mathrm{E}, \mathrm{NIWA}\right)$, Saint Denis $\left(-21^{\circ} \mathrm{S}, 55^{\circ} \mathrm{E}, \mathrm{CNRS} / \mathrm{Univ}^{\circ}\right.$ Réunion), Nairobi $\left(-1^{\circ} \mathrm{S}, 37^{\circ} \mathrm{E}\right.$, IFE (Institut für Fernerkundung, Univ. Bremen)), Mauna Loa $\left(20^{\circ} \mathrm{N}, 156^{\circ} \mathrm{W}, \mathrm{NIWA}\right)$, Izaña $\left(29^{\circ} \mathrm{N}, 16^{\circ} \mathrm{W}\right.$, INTA (Instituto Nacional de Técnica Aerospacial)), Observatoire de Haute-Provence $\left(44^{\circ} \mathrm{N}, 6^{\circ} \mathrm{E}, \mathrm{CNRS}\right)$, Jungfraujoch $\left(47^{\circ} \mathrm{N}, 8^{\circ} \mathrm{E}, \mathrm{BIRA}-\right.$ IASB (Belgian Institute for Space Aeronomy)), Zugspitze $\left(47^{\circ} \mathrm{N}, 12^{\circ} \mathrm{E}\right.$, IFE), Aberystwyth $\left(52^{\circ} \mathrm{N}, 4^{\circ} \mathrm{W}\right.$, Univ. Wales), Zvenigorod (55 $\mathrm{N}$, $36^{\circ}$ E, IAP (Institute of Atmospheric Physics)), Harestua $\left(60^{\circ} \mathrm{N}, 11^{\circ} \mathrm{E}\right.$, BIRA-IASB), Salekhard $\left(67^{\circ} \mathrm{N}, 67^{\circ} \mathrm{E}, \mathrm{CNRS} / \mathrm{CAO}(\mathrm{Central}\right.$ Aerological Observatory)), Zhigansk ( $\left.67^{\circ} \mathrm{N}, 123^{\circ} \mathrm{E}, \mathrm{CNRS} / \mathrm{CAO}\right)$, Sodankylä (67 $\mathrm{N}, 27^{\circ} \mathrm{E}, \mathrm{CNRS} / \mathrm{FMI}$ (Finnish Meteorological Institute)), Kiruna $\left(68^{\circ} \mathrm{N}, 21^{\circ} \mathrm{E}\right.$, NIWA), Scoresbysund $\left(70^{\circ} \mathrm{N}, 22^{\circ} \mathrm{W}, \mathrm{CNRS} / \mathrm{DMI}\right.$ (Danish Meteorological Institute)), Summit $\left(73^{\circ} \mathrm{N}, 39^{\circ} \mathrm{W}\right.$, IFE), Thule $\left(77^{\circ} \mathrm{N}, 69^{\circ} \mathrm{W}, \mathrm{DMI}\right)$. Results from stations deriving column data with stratospheric temperature cross-sections $\left(T_{X S}\right)$ for the spectral data retrieval are more accurate than stations using room or unknown temperature cross-sections.

non-validated instruments. Within this study, MIPAS $\mathrm{NO}_{2}$ vertical profiles have been compared to balloon-borne and satellite observations performed by different sensors. Furthermore, retrieved $\mathrm{NO}_{2}$ column amounts were compared to ground-based observations carried out within the NDACC network. Due to the strong diurnal variation of the $\mathrm{NO}_{2}$ species, non-coinciding validation measurements have been photochemically corrected to balance mismatches with the MIPAS observations. A retrieval processor comparison has also been included to better assess potential inaccuracies during the operational retrieval procedure which neglects nonLTE effects occurring in the upper stratosphere and mesosphere. A summary of the assessment of the individual comparisons is given in Table 7.

The MIPAS comparison to balloon-borne instruments revealed basically the best agreement between MIPAS and corresponding validating instruments. Except for the case of the SPIRALE flight in October 2002, where the measured $\mathrm{NO}_{2}$ profile had to be compared to MIPAS measurements carried out 4.5 days in advance, the agreement between MIPAS $\mathrm{NO}_{2}$ profiles and those observed during balloon flights carried out from tropical, mid-latitude, and arctic stations was found to be very good. Below about $35 \mathrm{~km}$ altitude, no significant bias between MIPAS and the balloon instruments exceeding the combined systematic errors has been found. Above this altitude region, a small positive bias (up to 10\%) in the MIPAS data has been detected. However, the mean devia- tion between MIPAS $\mathrm{NO}_{2}$ profiles and those measured by the balloon instruments is only $0.25 \mathrm{ppbv}(3.2 \%)$. The standard deviation of the differences between the measurements shows the same magnitude as the combined precision errors indicating that the precision part of the total error is characterized quite well. Nevertheless, it should be noted, that some MIPAS profiles are characterized by retrieval instabilities yielding to some oscillations in the profile shape.

A less clear picture emerges for the satellite comparison. The comparison to ACE exhibits only a small negative bias (about $-6 \%$ ) of MIPAS in the Arctic which appears not to be significant. The magnitude of the standard deviation of the mean relative difference is comparable to the combined precision error. The other independent satellite instruments (HALOE, SAGE II, POAM III) confirm in common for the spring-summer time period a negative bias of MIPAS in the Arctic and a positive bias in the Antarctic middle and upper stratosphere exceeding frequently the combined systematic error limits. Standard deviations of the mean relative differences are larger than the estimated combined precision errors. In middle latitudes, the comparison to HALOE reveals a positive bias of 5 to $26 \%$ between 12 and $2.5 \mathrm{hPa}$ (about $30-40 \mathrm{~km}$ ). In contrast, comparing to SAGE II this exhibits a mostly negative bias of +7 to $-40 \%$ in this altitude region. Bearing in mind that SAGE II has a positive bias to HALOE (L. Thomason, personal communication, 2004), this would at least partly explain this negative 
Table 7. Quality of the agreement between MIPAS $\mathrm{NO}_{2}$ data and independent observations carried out by different instruments. Time periods, latitudinal regions, approximate altitudes of the intercomparisons together with comments and ratings (++ very good; + good; $\circ$ fair) are summarized.

\begin{tabular}{|c|c|c|c|c|c|}
\hline Instrument & Time period & Latitude region & Approx. alt. & Comments & Rating \\
\hline \multicolumn{6}{|l|}{ Balloon comparison } \\
\hline MIPAS-B & Sep 02/March/July 03 & NH mid/high & $23-39 \mathrm{~km}$ & $\begin{array}{l}\text { small pos. bias } \geq 35 \mathrm{~km} \text {, mean deviation } \\
-2 \text { to }+4 \%\end{array}$ & ++ \\
\hline SPIRALE & Sep/Oct 02/Jan 03 & NH mid/high & $24-33 \mathrm{~km}$ & $\begin{array}{l}\text { large } \Delta \mathrm{t} \text { at mid-lat. ( } 4.5 \text { days), mean de- } \\
\text { viation }-7 \%\end{array}$ & + \\
\hline SAOZ & Sep 02/Feb/March 03 & low/NH mid/high & $23-35 \mathrm{~km}$ & $\begin{array}{l}\text { small pos. bias }>30 \mathrm{~km} \text {, mean deviation } \\
+3 \%\end{array}$ & ++ \\
\hline \multicolumn{6}{|l|}{ Satellite comparison } \\
\hline HALOE & July 02-Feb 04 & NH/SH mid/high & $23-40 \mathrm{~km}$ & $\begin{array}{l}\text { bias: pos. ( } 3 \text { to } 26 \%) \text {, neg. ( }-2 \text { to }-24 \% \text {, } \\
\text { only Arctic) }\end{array}$ & + \\
\hline SAGE II & July 02-Feb 04 & $\mathrm{NH} / \mathrm{SH} \mathrm{mid} / \mathrm{high}$ & $23-40 \mathrm{~km}$ & $\begin{array}{l}\text { bias: neg. }(+7 \text { to }-40 \%) \text {, pos. ( } 0 \text { to } 38 \% \text {, } \\
\text { only Antarctic) }\end{array}$ & $\circ$ \\
\hline POAM III & Nov $02-$ Nov 03 & NH/SH mid/high & $23-40 \mathrm{~km}$ & $\begin{array}{l}\mathrm{NH}:-46 \text { to }+15 \% \text {, SH: }-20 \text { to } 28 \% \text {, de- } \\
\text { pending on season }\end{array}$ & $\circ$ \\
\hline $\mathrm{ACE}$ & Feb/March 04 & NH high & $23-55 \mathrm{~km}$ & $\begin{array}{l}\text { small neg. bias }<32 \mathrm{~km} \text {, mean deviation } \\
-6 \%\end{array}$ & + \\
\hline MIPAS IMK/IAA & Sep 02/Feb/March 04 & NH mid/high & $24-70 \mathrm{~km}$ & $\begin{array}{l}\text { within } 5-10 \% \text {, polar winter up to } 40 \% \text {, } \\
\text { high variability }>50 \mathrm{~km}\end{array}$ & + \\
\hline \multicolumn{6}{|c|}{ Ground-based comparison } \\
\hline FTIR Kiruna & Feb-Sep 03 & NH high & $\geq 25 \mathrm{~km}$ & pos. bias $(+10 \%)$ & + \\
\hline UV-vis Harestua & July $02-$ Oct 03 & $\mathrm{NH}$ mid/high & $26.5-36.5 \mathrm{~km}$ & neg. bias $(-8 \%$, night; $-15 \%$, day) & $\circ$ \\
\hline NDACC UV-vis & Jan-Dec 03 & $\mathrm{NH} / \mathrm{SH}$ all & $\geq$ tropopause & $\begin{array}{l}\text { small neg. bias (mean agreement within } \\
10 \text { and } 30 \% \text { ) }\end{array}$ & $\circ$ \\
\hline
\end{tabular}

bias compared to MIPAS. The POAM III to MIPAS comparison (between about 25 and $40 \mathrm{~km}$ ) exhibits hemispheric differences from -7 to $28 \%$ in the southern and 0 to $-46 \%$ in the northern spring/summer hemisphere. However, differences between POAM and SAGE II and HALOE also sometimes exceed significantly the $10 \%$ limit (cp. Sect. 3.2.3). The slightly better agreement between MIPAS and HALOE compared to MIPAS and SAGE II /POAM III could be explained by the fact that the HALOE $\mathrm{NO}_{2}$ data is corrected by taking into account variations of the solar zenith angle along the line of sight. The high Antarctic winter (2003) deviations between MIPAS and POAM III could be connected with observations near and across the vortex edge and/or connected limitations of the correction with the photochemical model in this case. In this context it must be emphasized that whenever $\mathrm{NO}_{2}$ values are very high in the upper stratosphere and lower mesosphere, which was the case in the Antarctic polar region in winter 2003 (Funke et al., 2005b) and in the Arctic winter 2003/04, $\mathrm{NO}_{2}$ values retrieved by the MIPAS operational processor at $30 \mathrm{~km}$ and below suffer from very large errors since microwindows used by the ESA processor most probably do not contain significant information in the lower stratosphere under these extreme conditions (cp. Sect. 3.2.5). In contrast to the ESA operational proces- sor, the IMK/IAA retrieval code allows accurate inference of $\mathrm{NO}_{2}$ volume mixing ratios under consideration of all important non-LTE processes. Large differences between both retrieval results appear especially at higher altitudes above about 50 to $55 \mathrm{~km}$. These differences might be explained at least partly by non-LTE (under polar winter conditions). Below this altitude region mean differences between both processors remain within 5\% (during night) and up to $10 \%$ (during day) under undisturbed (September 2002) conditions and up to $40 \%$ under perturbed polar night conditions (February and March 2004). These differences are probably related to horizontal $\mathrm{NO}_{2}$ gradients, which are explicitly treated in the IMK/IAA retrieval, and differences in the retrieved temperature profiles.

The intercomparison of ground-based NDACC observations has shown that no significant bias between the FTIR measurements in Kiruna $\left(68^{\circ} \mathrm{N}\right)$ and MIPAS is visible in summer 2003. However, in autumn and winter, deviations are larger revealing a positive bias in the MIPAS partial columns of up to $43 \%$ in February 2003 for a measurement situation outside the polar vortex. The mean deviation over the whole comparison period remains within $10 \%$. In contrast to the mean positive bias detected from Kiruna, a mean negative bias of $15 \%$ for MIPAS daytime and $8 \%$ 
for nighttime observations has been determined for UV-vis comparisons over Harestua $\left(60^{\circ} \mathrm{N}\right)$. For nighttime events this bias clearly shows a seasonal variation with a negative bias in spring-summer and a positive bias in late summer-early fall. However, intercomparing the Harestua daytime observations with the (daytime) Kiruna measurements the detected biases to MIPAS show an opposite sign. Results of a pole-to-pole comparison of ground-based DOAS/UV-visible sunrise and MIPAS mid-morning column data has shown that the mean agreement in 2003 falls within the accuracy limit of the comparison method. However, a small negative bias of MIPAS is also visible, especially in the northern hemisphere data.

The intercomparison of independent instruments to MIPAS operational $\mathrm{NO}_{2}$ data has shown that MIPAS operational $\mathrm{NO}_{2}$ data are basically in good agreement with observations carried out by different independent validation instruments. The total MIPAS $\mathrm{NO}_{2}$ mean retrieval error was determined to be within a 10 to $20 \%$ confidence limit in the middle and lower stratosphere (below about $45 \mathrm{~km}$ ) while the systematic error should stay within a 5 to $10 \%$ error limit (Raspollini et al., 2006). The random part of the error typically ranges between about 5 and $15 \%$. No significant nonLTE error is expected below $50 \mathrm{~km}$ altitude. The ex ante estimated MIPAS error limits appear to be reasonable. Deviations between MIPAS and balloon experiments are small and virtually within the combined error limits for all considered flights in the Arctic, at mid-latitudes and the tropics. This holds also for many ground-based observations of the NDACC network while satellite comparisons show sometimes larger deviations, especially in the Arctic and Antarctic. Here, the photochemical correction of the $\mathrm{NO}_{2}$ data may also introduce significant errors in the comparison. Error estimates by Bracher et al. (2005) have shown that this uncertainty may reach up to $8 \%$ (HALOE) and up to $18 \%$ (SAGE II and POAM III) between 20 and $40 \mathrm{~km}$. Some systematic deviations could generally also be related to spectroscopy, since different spectral regions were used to derive $\mathrm{NO}_{2}$ data from observations of different instruments. Altogether, it can be indicated that MIPAS $\mathrm{NO}_{2}$ profiles yield valuable information on the vertical distribution of $\mathrm{NO}_{2}$ in the lower and middle stratosphere during day and night with an overall accuracy such that the data are useful for scientific studies. In cases where extremely high $\mathrm{NO}_{2}$ occurs in the mesosphere (polar winter) retrieval results in the stratosphere are less accurate than under undisturbed atmospheric conditions. In the upper stratosphere and mesosphere, MIPAS errors generally increase and the total error exceeds the 100\% limit above $50 \mathrm{~km}$ (Raspollini et al., 2006) such that MIPAS operational $\mathrm{NO}_{2}$ data are therefore less reliable in this altitude region.

Acknowledgements. Financial support by the DLR (Project 50EE0020) and ESA for the MIPAS-B balloon flights is gratefully acknowledged. We thank the Centre National d'Etudes Spatiales (CNES) balloon launching team and the Swedish Space Corporation (SSC) Esrange people for excellent balloon operations and the Free University of Berlin (K. Grunow and B. Naujokat) for meteorological support and trajectory calculations. Most of the SAOZ balloon-borne flights were supported by CNES and the European Space Agency (ESA) within the ESABC project. In addition, the tropical SAOZ flights were partly supported by the European Commission (EC) Hibiscus project. The Canadian Space Agency (CSA), Environment Canada, Scientific Instrumentation Limited, and MANTRA PI K. Strong (University of Toronto) are also acknowledged for flying SAOZ during the MANTRA 2002 and MANTRA 2004 campaigns. The authors would like to thank K. Walker, P. Bernath and C. Boone for providing ACE data. We thank the HALOE group at Hampton University, especially to J. M. Russell III, and at NASA LaRC, especially to E. Thompson, and the SAGE II group at NASA LaRC, especially to L. Thomason, and the NASA Radiation and Aerosol Branch for providing the data and information on these data. We acknowledge the POAM III team from NRL, CNES and ONR for providing the data and information on these data. The validation work by IUP-IFE Bremen was funded in part by BMBF (FKZ 01 SF994) and ESA/ESRIN under the SciLoV project. The IAA team was supported by the Spanish project ESP2004-01556 and EC FEDER funds The ground-based data used in this publication were obtained as part of the Network for the Detection of Atmospheric Composition Change (NDACC) and are publicly available (see http://www.ndacc.org).

Edited by: P. Espy

\section{References}

Abrams, M. C., Chang, A. Y., Gunson, M. R., Abbas, M. M., Goldman, A., Irion, F. W., Michelsen, H. A., Newchurch, M. J., Rinsland, C. P., Stiller, G. P., and Zander, R.: On the assessment and uncertainty of atmospheric trace gas burden measurements with high resolution infrared solar occultation spectra from space by the ATMOS experiment, Geophys. Res. Lett., 23(17), 23372340, doi:10.1029/96GL01794, 1996.

Amekudzi, L. K., Bracher, A., Meyer, J., Rozanov, A., Bovensmann, H., and Burrows J. P.: Lunar occultation with SCIAMACHY: First retrieval results, Adv. Space Res., 36, 906-914, 2005.

Bernath, P. F., McElroy, C. T., Abrams, M. C., et al.: Atmospheric Chemistry Experiment (ACE): Mission Overview, Geophys. Res. Lett., 32, L15S01, doi:10.1029/2005GL022386, 2005.

Bertaux, J. L., Mégie, G., Widemann, T., Chassefière, E., Pellinen, R., Korylla, E., Korpela, S., and Simon, P.: Monitoring of ozone trend by stellar occultations: The GOMOS Instrument, Adv. Space Res., 11, 237-242, 1991.

Blumenstock, T., Fischer, H., Friedle, A., Hase, F., and Thomas, P.: Column amounts of $\mathrm{ClONO}_{2}, \mathrm{HCl}, \mathrm{HNO}_{3}$, and $\mathrm{HF}$ from ground-based FTIR measurements made near Kiruna, Sweden in late winter 1994, J. Atmos. Chem., 26(3), 311-321, 1997.

Bovensmann, H., Burrows, J. P., Buchwitz, M., Frerick, J., Noël, S., Rozanov, V. V., Chance, K. V., and Goede, A. H. P.: SCIAMACHY - Mission objectives and measurement modes, J. Atmos. Sci., 56, 125-150, 1999.

Bracher, A., Sinnhuber, M., Rozanov, A., and Burrows, J. P.: Using a photochemical model for the validation of $\mathrm{NO}_{2}$ satellite measurements at different solar zenith angles, Atmos. Chem. Phys., 5, 393-408, 2005, http://www.atmos-chem-phys.net/5/393/2005/. 
Brasseur, G. and Solomon, S.: Aeronomy of the middle atmosphere (third edition), Atmos. Oceanograph. Sci. Lib., Springer, Dordrecht, The Netherlands, p. 336, 2005.

Carlotti, M.: Global-fit approach to the analysis of limb-scanning atmospheric measurements, Appl. Opt., 27, 3250-3254, 1988.

Chance, K., Traub, W. A., Johnson, D. G., Jucks, K. W., Ciarpallini, P., Stachnik, R. A., Salawitch, R. J., and Michelsen, H. A.: Simultaneous measurements of stratospheric $\mathrm{HO}_{\mathrm{X}}, \mathrm{NO}_{\mathrm{X}}$, and $\mathrm{Cl}_{\mathrm{X}}$ : Comparison with a photochemical model, J. Geophys. Res., 101, 9031-9043, 1996.

Chu, W. P. and McCormick, M. P.: SAGE observations of stratospheric nitrogen dioxide, J. Geophys. Res., 91, 5465-5476, 1986.

Coffey, M., Mankin, W., and Goldman, A.: Simultaneous spectroscopic determination of the latitudinal, seasonal, and diurnal variability of stratospheric $\mathrm{N}_{2} \mathrm{O}, \mathrm{NO}, \mathrm{NO}_{2}$, and $\mathrm{HNO}_{3}$, J. Geophys. Res., 86, 7331-7341, 1981.

Cunnold, D. M., Zawodny, J. M., Chu, W. P., Pommereau, J. P., Goutail, F., Lenoble, J., McCormick, M. P., Veiga, R. E., Murcray, D., Iwagami, N., Shibasaki, K., Simon, P. C., and Peetermans, W.: Validation of SAGE II $\mathrm{NO}_{2}$ measurements, J. Geophys. Res., 96, 12913-12 925, 1991.

De Mazière, M., Van Roozendael, M., Hermans, C., Simon, P. C., Demoulin, P., Roland, G., and Zander, R.: Quantitative evaluation of the post - Mount Pinatubo $\mathrm{NO}_{2}$ reduction and recovery, based on 10 years of Fourier transform infrared and UV-visible spectroscopic measurements at Jungfraujoch, J. Geophys. Res., 103(D9), 10 849-10 858, doi:10.1029/97JD03362, 1998.

Denis, L., Roscoe, H. K., Chipperfield, M. P., Van Roozendael, M., and Goutail, F.: A new software suite for $\mathrm{NO}_{2}$ vertical profile retrieval from ground-based zenith-sky spectrometers, J. Quant. Spectrosc. Ra., 92, 321-333, 2005.

Dessler, A. E., Kawa, S. R., Considine, D. B., Waters, J. W., Froidevaux, L., and Kumer, J. B.: UARS measurements of $\mathrm{ClO}$ and $\mathrm{NO}_{2}$ at 40 and $46 \mathrm{~km}$ and implications for the model "ozone deficit”, Geophys. Res. Lett., 23, 339-342, 1996.

Errera, Q. and Fonteyn, D.: Four-dimensional variational chemical assimilation of CRISTA stratospheric measurements, J. Geophys. Res., 106, 12 253-12 265, 2001.

Fischer, H. and Oelhaf, H.: Remote sensing of vertical profiles of atmospheric trace constituents with MIPAS limb-emission spectrometers, Appl. Opt., 35, 2787-2796, 1996.

Flaud, J.-M., Piccolo, C., Carli, B., Perrin, A., Coudert, L. H., Teffo, J.-L., and Brown, L. R.: Molecular line parameters for the MIPAS (Michelson Interferometer for Passive Atmospheric Sounding) experiment, J. Atmos. Ocean. Opt., 16, 172-182, 2003.

Friedl-Vallon, F., Maucher, G., Seefeldner, M., Trieschmann, O., Kleinert, A., Lengel, A., Keim, C., Oelhaf, H., and Fischer, H.: Design and characterization of the balloon-borne Michelson Interferometer for Passive Atmospheric Sounding (MIPAS-B2), Appl. Opt., 43, 3335-3355, 2004.

Funke, B., López-Puertas, M., Stiller, G. P., von Clarmann, T., and Höpfner, M.: A new non-LTE retrieval method for atmospheric parameters from MIPAS-Envisat emission spectra, Adv. Space Res., 27(6-7), 1099-1104, 2001.

Funke, B., López-Puertas, M., von Clarmann, T., Stiller, G. P., Fischer, H., Glatthor, N., Grabowski, U., Höpfner, M, Kellmann, S., Kiefer, M., Linden, A., Mengistu Tsidu, G., Milz, M., Steck, T., and Wang, D. Y.: Retrieval of stratospheric $\mathrm{NO}_{\mathrm{x}}$ from
5.3 and $6.2 \mu \mathrm{m}$ nonlocal thermodynamic equilibrium emissions measured by Michelson Interferometer for Passive Atmospheric Sounding (MIPAS) on Envisat, J. Geophys. Res., 110, D09302, doi:10.1029/2004JD005225, 2005a.

Funke, B., López-Puertas, M., Gil-López, S., von Clarmann, T., Stiller, G. P., Fischer, H., and Kellmann, S.: Downward transport of upper atmospheric NOx into the polar stratosphere and lower mesosphere during the Antarctic 2003 and Arctic 2002/2003 winters, J. Geophys. Res., 110, D24308, doi:10.1029/2005JD006463, 2005b.

Gille, J. C. and Russell III, J. M.: The Limb Infrared Monitor of the Stratosphere: Experiment description, performance, and results, J. Geophys. Res., 89, 5125-5140, 1984.

Gordley, L. L., Russell, J. M. I., Mickley, L. J., Frederick, J. E., Park, J. H., Stone, K. A., Beaver, G. M., McInerney, J. M., Deaver, L. E., Toon, G. C., Murcray, F. J., Blatherwick, R. D., Gunson, M. R., Abbatt, J. P. D., Mauldin, R. L. I., Mount, G. H., Sen, B., and Blavier, J.-F.: Validation of nitric oxide and nitrogen dioxide measurements made by the Halogen Occultation Experiment for UARS platform, J. Geophys. Res., 101(D6), 10 241-10 266, doi:10.1029/95JD02143, 1996.

Hase, F., Hannigan, J. W., Coffey, M. T., Goldman, A., Höpfner, M., Jones, N. B., Rinsland, C. P., and Wood, S. W.: Intercomparison of retrieval codes used for the analysis of highresolution, ground-based FTIR measurements, J. Quant. Spectrosc. Ra., 87(1), 25-52, 2004.

Hendrick, F., Barret, B., Van Roozendael, M., Boesch, H., Butz, A., De Mazière, M., Goutail, F., Hermans, C., Lambert, J.-C., Pfeilsticker, K., and Pommereau, J.-P.: Retrieval of nitrogen dioxide stratospheric profiles from ground-based zenith-sky UVvisible observations: validation of the technique through correlative comparisons, Atmos. Chem. Phys., 4, 2091-2106, 2004, http://www.atmos-chem-phys.net/4/2091/2004/.

Höpfner, M., Oelhaf, H., Wetzel, G., Friedl-Vallon, F., Kleinert, A., Lengel, A., Maucher, G., Nordmeyer, H., Glatthor, N., Stiller, G., von Clarmann, T., Fischer, H., Kröger, C., and Deshler, T.: Evidence of scattering of tropospheric radiation by PSCs in mid-IR limb emission spectra: MIPAS-B observations and KOPRA simulations, Geophys. Res. Lett., 29(8), 1278, doi:10.1029/2001GL014443, 2002.

Koike, M., Kondo, Y., Matthews, W. A., Johnston, P. V., Nakajima, H., Kawaguchi, A., Nakane, H., Murata, I., Budiyono, A., Kanada, M., and Toriyama, N.: Assessment of the uncertainties in the $\mathrm{NO}_{2}$ and $\mathrm{O}_{3}$ measurements by visible spectrometers, $\mathrm{J}$. Atmos. Chem., 32, 121-145, 1999.

Kondo, Y., Matthews, W. A., Iwata, A., and Takagi, M.: Measurements of nitric oxide from $7-32 \mathrm{~km}$ and its diurnal variation in the stratosphere, J. Geophys. Res., 90, 3813-3819, 1985.

Kouker, W., Langbein, I., Reddmann, T., and Ruhnke, R.: The Karlsruhe simulation model of the middle atmosphere (KASIMA), version 2, Rep. FZKA 6278, Forschungszentrum Karlsruhe GmbH, Karlsruhe, Germany, 1999.

Lambert, J.-C., Van Roozendael, M., De Mazière, M., Simon, P. C., Pommereau, J.-P., Goutail, F., Sarkissian, A., and Gleason, J. F.: Investigation of pole-to-pole performances of spaceborne atmospheric chemistry sensors with the NDSC, J. Atmos. Sci., 56, 176-193, 10.1175/1520-0469, 1999.

Lambert, J.-C., Hansen, G., Soebijanta, V., Thomas, W., Van Roozendael, M., Balis, D. S., Fayt, C., Gerard, P., Gleason, 
J. F., Granville, J., Labow, G., Loyola, D., Van Geffen, J. H. G., Van Oss, R. F., Zehner, C., and Zerefos, C. S.: ERS-2 GOME GDP3.0 Implementation and validation, ESA Technical Note ERSE-DTEX-EOAD-TN-02-0006, edited by: Lambert, J.C. (IASB), 138 pp., November 2002.

Langematz, U., Labitzke, K., and Reimer, E.: Synoptic analysis and trajectories during the MAP/GLOBUS campaign 1983. Planet. Space Sci., 35, 525-538, doi:10.1016/0032-0633(87)90120-6, 1987.

López-Puertas, M. and Taylor, F. W.: Non-LTE radiative transfer in the atmosphere, World Sci. Pub., River Edge, N. J., 2001.

Lumpe, J. D., Bevilacqua, R. M., Hoppel, K. W., and Randall, C. E.: POAM III retrieval algorithm and error analysis, J. Geophys. Res., 107(D21), 4575, doi:10.1029/2002JD002137, 2002.

Marchand, M., Bekki, S., Hauchecorne, A., and Bertaux, J.-L.: Validation of the self-consistency of GOMOS $\mathrm{NO}_{3}, \mathrm{NO}_{2}$ and $\mathrm{O}_{3}$ data using chemical data assimilation, Geophys. Res. Lett., 31, L10107, doi:10.1029/2004GL019631, 2004.

McHugh, M., Magill, B., Walker, K. A., Boone, C. D., Bernath, P. F., and Russell III, J. M.: Comparison of atmospheric retrievals from ACE and HALOE, Geophys. Res. Lett., 32, L15S10, doi:10.1029/2005GL022403, 2005.

McKenzie, R. L., Johnston, P. V., McElroy, C. T., Kerr, J. B., and Solomon, S.: Altitude distributions of stratospheric constituents from ground-based measurements at twilight, J. Geophys. Res., 96(D8), 15 499-15 511, doi:10.1029/91JD01361, 1991.

Meyer, J., Bracher, A., Rozanov, A., Schlesier, A. C., Bovensmann, H., and Burrows, J. P.: Solar occultation with SCIAMACHY: algorithm description and first validation, Atmos. Chem. Phys., 5, 1589-1604, 2005,

http://www.atmos-chem-phys.net/5/1589/2005/.

Moreau, G., Robert, C., Catoire, V., Chartier, M., Camy-Peyret, C., Huret, N., Pirre, M., and Pomathiod, L.: SPIRALE: A multispecies in situ balloon-borne instrument with six tunable diode laser spectrometers, Appl. Opt., 44, 5972-5989, 2005.

Nakajima, H., Sugita, T., Yokota, T., Ishigaki, T., Mogi, Y., Araki, N., Waragai, K., Kimura, N., Iwazawa, T., Kuze, A., Tanii, J., Kawasaki, H., Horikawa, M., Togami, T., Uemura, N., Kobayashi, H., and Sasano, Y.: Characteristics and performance of the Improved Limb Atmospheric Spectrometer-II (ILAS-II) on board the ADEOS-II satellite, J. Geophys. Res., 111, D11S01, doi:10.1029/2005JD006334, 2006.

Nasa Langley Research Center: SAGE III - The Stratospheric Aerosol and Gas Experiment III, SAGE III instrument, http: //www-sage3.larc.nasa.gov/, 2006.

Newchurch, M. J., Allen, M., Gunson, M. R., Salawitch, R. J., Collins, G. B., Huston, K. H., Abbas, M. M., Abrams, M. C., Chang, A. Y., Fahey, D. W., Gao, R. S., Irion, F. W., Loewenstein, M., Manney, G. L., Michelsen, H. A., Podolske, J. R., Rinsland, C. P., and Zander, R.: Stratospheric $\mathrm{NO}$ and $\mathrm{NO}_{2}$ abundances from ATMOS solar-occultation measurements, Geophys. Res. Lett., 23, 2373-2376, 1996.

Notholt, J. and Schrems, O.: Ground-based FTIR measurements of vertical column densities of several trace gases above Spitsbergen, Geophys. Res. Lett., 21(13), 1355-1358, doi:10.1029/93GL01786, 1994.

Noxon, J. F., Whipple Jr., E. C., and Hyde, R. S.: Stratospheric $\mathrm{NO}_{2}$. 1. Observational method and behavior at mid-latitude, J. Geophys. Res., 84, 5047-5065, 1979.
Payan, S., Camy-Peyret, C., Jeseck, P. Hawat, T., Pirre, M., Renard, J.-B., Robert, C., Lefèvre, F., Kanzawa, H., and Sasano, Y.: Diurnal and nocturnal distribution of stratospheric $\mathrm{NO}_{2}$ from solar and stellar occultation measurements in the Arctic vortex: Comparison with models and ILAS satellite measurements, J. Geophys. Res., 104, 21 585-21 593, 1999.

Pfeilsticker, K. and Platt, U.: Airborne Measurements during the Arctic Stratospheric Experiment: Observation of $\mathrm{O}_{3}$ and $\mathrm{NO}_{2}$, Geophys. Res. Lett. 21, 1375-1378, 1994.

Piters, A. J. M., Bramstedt, K., Lambert, J.-C., and Kirchhoff, B.: Overview of SCIAMACHY validation: 2002-2004, Atmos. Chem. Phys., 6, 127-148, 2006,

http://www.atmos-chem-phys.net/6/127/2006/.

Pommereau, J.-P. and Goutail, F.: $\mathrm{O}_{3}$ and $\mathrm{NO}_{2}$ groundbased measurements by visible spectroscopy during Arctic winter and spring, 1988, Geophys. Res. Lett., 15, 891-894, 1988.

Pommereau, J.-P. and Piquard, J.: Ozone and nitrogen dioxide vertical distributions by uv-visible solar occultation from balloons, Geophys. Res. Lett., 21, 1227-1230, 1994.

Randall C. E., Rusch, D. W., Bevilacqua, R. M., Hoppel, K. W., and Lumpe, J. D.: Polar ozone and aerosol measurement (POAM) II stratospheric $\mathrm{NO}_{2}$, 1993-1996, J. Geophys. Res., 103, $28361-$ 28371, 1998.

Randall, C. E., Lumpe, J. D., Bevilacqua, R. M., Hoppel, K. W., Shettle, E. P., Rusch, D. W., Gordley, L. L., Kreher, K., Pfeilsticker, K., Boesch, H., Toon, G., Goutail, F., and Pommereau, J.-P.: Validation of POAM III $\mathrm{NO}_{2}$ measurements, J. Geophys. Res., 107(D20), 4432, doi:10.1029/2001JD001520, 2002.

Raspollini, P., Belotti, C., Burgess, A., Carli, B., Carlotti, M., Ceccherini, S., Dinelli, B. M., Dudhia, A., Flaud, J.-M., Funke, B., Höpfner, M., López-Puertas, M., Payne, V., Piccolo, C., Remedios, J. J., Ridolfi, M., and Spang, R.: MIPAS level 2 operational analysis, Atmos. Chem. Phys., 6, 5605-5630, 2006,

http://www.atmos-chem-phys.net/6/5605/2006/.

Reburn, W. J., Remedios, J. J., Morris, P. E., Rodgers, C. D., Taylor, F. W., Kerridge, B. J., Knight, R. J., Ballard, J., Kumer, J. B., and Massie, S. T.: Validation of nitrogen dioxide measurements from the Improved Stratospheric and Mesospheric Sounder, J. Geophys. Res., 101, 9873-9895, 1996.

Reimer, E. and Kaupp, H.: Source identification of odour compounds using trajectories, Proc. ECO-INFORMA 97, EcoInforma Press, Bayreuth, 572-577, 1997.

Renard, J.-B., Pirre, M., Robert, C., Moreau, G., Huguenin, D., and Russell III, J. M.: Nocturnal vertical distribution of stratospheric $\mathrm{O}_{3}, \mathrm{NO}_{2}$ and $\mathrm{NO}_{3}$ from balloon measurements, J. Geophys. Res., 101, 28 793-28 804, 1996.

Rodgers, C.: Inverse methods for atmospheric sounding: Theory and practice, World Sci. Pub., River Edge, N. J., 2000.

Roscoe, H., Kerridge, B., Gray, L., Wells, R., and Pyle, J.: Simultaneous measurements of stratospheric $\mathrm{NO}$ and $\mathrm{NO}_{2}$ and their comparison with model predictions, J. Geophys. Res., 91, 54055419, 1986.

Roscoe, H. K., Johnston, P. V., Van Roozendael, M., et al.: Slant column measurements of $\mathrm{O}_{3}$ and $\mathrm{NO}_{2}$ during the NDSC intercomparison of zenith-sky UV-visible spectrometers in June 1996, J. Atmos. Chem., 32, 281-314, 1999.

Rothman, L. S., Jacquemart, D., Barbe, A., et al.: The HITRAN 2004 molecular spectroscopic database, J. Quant. Spectrosc. Ra., 96, 139-204, 2005. 
Rozanov A., Bovensmann, H., Bracher, A., Hrechanyy, S., Rozanov, V., Sinnhuber, M., Stroh, F., and Burrows, J. P.: $\mathrm{NO}_{2}$ and $\mathrm{BrO}$ vertical profile retrieval from SCIAMACHY limb measurements: Sensitivity studies, Adv. Space Res., 36, 846-854, 2005.

Russell III, J. M., Farmer, C., Rinsland, C., Zander, R., Froidevaux, L., Toon, G., Gao, B., Shaw, J., and Gunson, M.: Measurements of odd nitrogen compounds in the stratosphere by the ATMOS experiment on Spacelab 3, J. Geophys. Res., 93, 1718-1736, 1988.

Russell III, J. M., Gordley, L. L., Gordley, J. H., Park, J. H., Drayson, S. R., Hesketh, W. D., Cicerone, R. J., Tuck, A. F., Frederick, J. E., Harries, J. E., and Crutzen, P. J.: The Halogen Occultation Experiment, J. Geophys. Res., 98, 10777-10797, 1993.

Sasano, Y., Suzuki, M., Yokota, T., and Kanzawa, H.: Improved Limb Atmospheric Spectrometer (ILAS) for stratospheric ozone layer measurements by solar occultation technique, Geophys. Res. Lett., 26, 197-200, 1999.

Sen, B., Toon, G. C., Osterman, G. B., Blavier, J.-F., Margitan, J. J., Salawitch, R. J., and Yue, G. K.: Measurements of reactive nitrogen in the stratosphere, J. Geophys. Res., 103, 3571-3585, 1998.

Stiller, G. P., von Clarmann, T., Funke, B., Glatthor, N., Hase, F., Höpfner, M., and Linden, A.: Sensitivity of trace gas abundances retrievals from infrared limb emission spectra to simplifying approximations in radiative transfer modeling, J. Quant. Spectrosc. Ra., 72(3), 249-280, 2002.

Sussmann, R., Stremme, W., Burrows, J. P., Richter, A., Seiler, W., and Rettinger, M.: Stratospheric and tropospheric $\mathrm{NO}_{2}$ variability on the diurnal and annual scale: a combined retrieval from ENVISAT/SCIAMACHY and solar FTIR at the Permanent Ground-Truthing Facility Zugspitze/Garmisch, Atmos. Chem. Phys., 5, 2657-2677, 2005, http://www.atmos-chem-phys.net/5/2657/2005/.

Vandaele, A. C., Hermans, C., Simon, P. C., Carleer, M., Colin, R., Fally, S., Merienne, M.-F., Jenouvrier, A., and Coquart, B.: Measurements of $\mathrm{NO}_{2}$ absorption cross-section from $42000 \mathrm{~cm}^{-1}$ to $10000 \mathrm{~cm}^{-1}(238-1000 \mathrm{~nm})$ at $220 \mathrm{~K}$ and $294 \mathrm{~K}$, J. Quant. Spectrosc. Ra., 59, 171-184, 1998.
Vandaele, A. C., Fayt, C., Hendrick, F., et al.: An intercomparison campaign of ground-based UV-visible measurements of $\mathrm{NO}_{2}, \mathrm{BrO}$, and $\mathrm{OClO}$ slant columns: Methods of analysis and results for $\mathrm{NO}_{2}$, J. Geophys. Res., 110, D08305, doi:10.1029/2004JD005423, 2005.

von Clarmann, T., Chidiezie Chineke, T., Fischer, H., Funke, B., García-Comas, M., Gil-López, S., Glatthor, N., Grabowski, U., Höpfner, M., Kellmann, S., Kiefer, M., Linden, A., LópezPuertas, M., López-Valverde, M. A., Mengistu Tsidu, G., Milz, M., Steck, T., and Stiller, G. P.: Remote sensing of the middle atmosphere with MIPAS, in: Remote sensing of clouds and the atmosphere VII, edited by: Schäfer, K., Lado-Bordowsky, O., Comerón, A., and Picard, R. H., SPIE Proc., 4882, 172-183, 2003.

von Clarmann, T.: Validation of remotely sensed profiles of atmospheric state variables: strategies and terminology, Atmos. Chem. Phys., 6, 4311-4320, (Addendum, Atmos. Chem. Phys., 6, 5547, 2006.) 2006.

Webster, C., May, R., Toumi, R., and Pyle, J.: Active nitrogen partitioning and the nighttime formation of $\mathrm{N}_{2} \mathrm{O}_{5}$ in the stratosphere: Simultaneous in situ measurements of $\mathrm{NO}, \mathrm{NO}_{2}, \mathrm{HNO}_{3}, \mathrm{O}_{3}$, and $\mathrm{N}_{2} \mathrm{O}$ using the BLISS diode laser spectrometer, J. Geophys. Res., 95, 13 851-13 866, 1990.

Wetzel, G., Oelhaf, H., von Clarmann, T., Fischer, H., FriedlVallon, F., Maucher, G., Seefeldner, M., Trieschmann, O., and Lefèvre, F.: Vertical profiles of $\mathrm{N}_{2} \mathrm{O}_{5}, \mathrm{HO}_{2} \mathrm{NO}_{2}$, and $\mathrm{NO}_{2}$ inside the Arctic vortex, retrieved from nocturnal MIPAS-B2 infrared limb emission measurements in February 1995, J. Geophys. Res., 102, 19 177-19 186, 1997.

Wetzel, G., Oelhaf, H., Friedl-Vallon, F., Kleinert, A., Lengel, A., Maucher, G., Nordmeyer, H., Ruhnke, R., Nakajima, H., Sasano, Y., Sugita, T., and Yokota, T.: Intercomparison and validation of ILAS-II version 1.4 target parameters with MIPAS-B measurements, J. Geophys. Res., 111, D11S06, doi:10.1029/2005JD006287, 2006. 